\title{
Combined effects of surface conditions, boundary layer dynamics and chemistry on diurnal SOA evolution
}

\author{
R. H. H. Janssen ${ }^{1}$, J. Vilà-Guerau de Arellano ${ }^{2}$, L. N. Ganzeveld ${ }^{1}$, P. Kabat ${ }^{3,1}$, J. L. Jimenez ${ }^{4}$, D. K. Farmer ${ }^{5}$, \\ C. C. van Heerwaarden ${ }^{6}$, and I. Mammarella ${ }^{7}$ \\ ${ }^{1}$ Earth System Science and Climate Change, Wageningen University and Research Centre, Wageningen, The Netherlands \\ ${ }^{2}$ Meteorology and Air Quality Section, Wageningen University and Research Centre, Wageningen, The Netherlands \\ ${ }^{3}$ International Institute for Applied Systems Analysis, Laxenburg, Austria \\ ${ }^{4}$ CIRES and Department of Chemistry and Biochemistry, University of Colorado, Boulder, CO, USA \\ ${ }^{5}$ Department of Chemistry, Colorado State University, Fort Collins, CO, USA \\ ${ }^{6}$ Max Planck Institute for Meteorology, Hamburg, Germany \\ ${ }^{7}$ Department of Physics, University of Helsinki, Helsinki, Finland
}

Correspondence to: R. H. H. Janssen (ruud.janssen@wur.nl)

Received: 26 January 2012 - Published in Atmos. Chem. Phys. Discuss.: 11 April 2012

Revised: 25 June 2012 - Accepted: 4 July 2012 - Published: 1 August 2012

\begin{abstract}
We study the combined effects of land surface conditions, atmospheric boundary layer dynamics and chemistry on the diurnal evolution of biogenic secondary organic aerosol in the atmospheric boundary layer, using a model that contains the essentials of all these components. First, we evaluate the model for a case study in Hyytiälä, Finland, and find that it is able to satisfactorily reproduce the observed dynamics and gas-phase chemistry. We show that the exchange of organic aerosol between the free troposphere and the boundary layer (entrainment) must be taken into account in order to explain the observed diurnal cycle in organic aerosol (OA) concentration. An examination of the budgets of organic aerosol and terpene concentrations show that the former is dominated by entrainment, while the latter is mainly driven by emission and chemical transformation. We systematically investigate the role of the land surface, which governs both the surface energy balance partitioning and terpene emissions, and the large-scale atmospheric process of vertical subsidence. Entrainment is especially important for the dilution of organic aerosol concentrations under conditions of dry soils and low terpene emissions. Subsidence suppresses boundary layer growth while enhancing entrainment. Therefore, it influences the relationship between organic aerosol and terpene concentrations. Our findings indicate that the diurnal evolution of secondary organic aerosols (SOA) in the boundary layer is the result of cou-
\end{abstract}

pled effects of the land surface, dynamics of the atmospheric boundary layer, chemistry, and free troposphere conditions. This has potentially some consequences for the design of both field campaigns and large-scale modeling studies.

\section{Introduction}

A large part of submicron atmospheric particulate material is organic (Hallquist et al., 2009; Jimenez et al., 2009). Secondary organic aerosols (SOA) which are formed in the atmosphere from oxidation of high-volatility precursors are an important contributor to the total organic aerosol budget. The importance of SOA in new particle formation (Metzger et al., 2010; Laaksonen et al., 2008; O'Dowd et al., 2002) and the growth of atmospheric particles to cloud condensation nuclei (Riipinen et al., 2011; Slowik et al., 2010; Tunved et al., 2006 ) is well established. Formation of SOA from gas-phase species depends on the emissions of these species and their processing in the atmosphere. When emitted at the land surface, they enter into the atmospheric boundary layer (BL), the lowest part of the atmosphere, which is characterized by strong turbulent motions that are largely influenced by the underlying land surface and the free troposphere (FT) on top of it (de Bruin, 1983; van Heerwaarden et al., 2009). Acting as a buffer between the surface processes and the FT, 


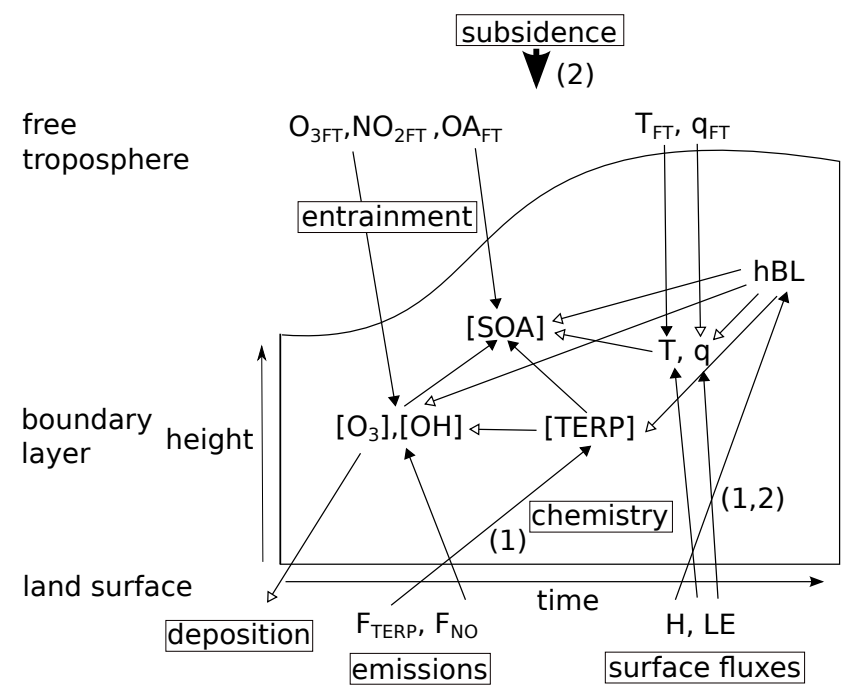

Fig. 1. Scheme of the interactions in and the boundaries of the system studied in this work. The numbers relate to the forcings of the system that are varied in the sensitivity analysis. Closed arrows indicate a positive relation, open arrows a negative relation and processes are indicated in the boxes.

the BL dynamics affect the processing of aerosol precursor species and the partitioning into the aerosol phase of their low-volatility reaction products.

Here we aim to systematically study the role of the diurnal variability of dynamics and chemical transformation on the evolution of organic aerosol. We do this by modeling a case study and conducting a set of sensitivity analyses using MXLCH-SOA, a coupled model of BL dynamics, land surface, gas-phase chemistry and gas/particle partitioning, aiming to determine the role of different processes in controlling the diurnal variability in OA. A schematic overview of the studied system is given in Fig. 1. It is important to note that we strive for a balance between all relevant components of the system and therefore include the land surface, BL dynamics, chemistry and gas/particle partitioning in a way that keeps the essentials of all components. This allows us to systematically study the whole system in a coupled approach while avoiding excessive complexity. Thus, we expand upon modeling studies that take the diurnal variability of BL characteristics on SOA formation into account using box models with prescribed diurnal cycles of temperature, humidity, boundary layer height, and oxidants (Sheehan and Bowman, 2001; Bowman and Karamalegos, 2002; Dzepina et al., 2009), or applying a fixed BL height, thereby neglecting the effects of entrainment on BL growth and reactant concentrations (Tunved et al., 2006; Riipinen et al., 2011). Besides, regional and global chemical transport models used for simulating SOA formation are usually forced by offline meteorology (Lane et al., 2008; Slowik et al., 2010; Riipinen et al., 2011), which hinders the ability to study their sensitivity to meteorological and land surface boundary con- ditions. In contrast, in our approach the dynamics and chemistry are solved simultaneously, which allows for an analysis of different cases in which BL growth and entrainment are driven by varying land surface and FT conditions. Moreover, in our approach we are able to explicitly calculate the contributions of the different processes to the budgets of reactants, since MXLCH-SOA contains basic parametrizations of the relevant processes based on sound physical and chemical assumptions.

As a first step we validate MXLCH-SOA with observations of BL dynamics and gas-phase chemistry collected at the SMEAR II measurement station at Hyytiälä, Finland. It is located in the boreal forest which is an important source of SOA, mainly from terpene oxidation (e.g. Tunved et al., 2006). Then we perform a budget analysis of the main contributions to terpene and organic aerosol mass in time, including emissions, entrainment, chemistry and partitioning. Finally, we analyze the sensitivity of BL organic aerosol evolution to (1) the land surface conditions, in terms of surface heat flux partitioning which drives the exchange between the FT and the BL, and terpene emissions and (2) land surface conditions (heat flux partitioning), entrainment and the largescale atmospheric process of vertical subsidence associated with the presence of a high pressure system. The experiments are based on a case study for the boreal forest region. However, since our focus is on understanding the processes that occur in each BL in which SOA formation occurs, we will discuss the general applicability of the findings for this case study and their implications for field campaigns and largescale modeling.

\section{Methods}

In this section we briefly introduce the methods used to represent the BL dynamics and gas-phase chemistry, including SOA formation through oxidation of volatile organic compounds (VOCs), in MXLCH-SOA. Furthermore, we describe the case study and the numerical experiments that we performed.

\subsection{Dynamics of the boundary layer: mixed layer approach}

Mixed layer theory (Lilly, 1968; Tennekes, 1973) is an approximation for mixing in the BL under convective conditions. Under this approximation scalars and chemical species are instantaneously and perfectly mixed throughout the BL due to the high turbulent intensity (Vilà-Guerau de Arellano et al., 2011). In this way, the mixed layer approach is comparable to a homogeneous reactive box in which chemical transformations take place. Within this approach, the BL grows due to the entrainment of dry air at the interface between the FT and the BL, which is induced by the buoyancy flux at the surface. These processes influence the 
Table 1. Chemical reaction scheme used in the numerical experiments of MXLCH-SOA. In the reaction rate functions, $T$ is the absolute temperature and $\chi$ is the solar zenith angle. First-order reaction rates are in $\mathrm{s}^{-1}$ and second-order reactions are in $\mathrm{cm}^{3} \mathrm{molec}^{-1} \mathrm{~s}^{-1}$. PRODUCTS are reaction products which are not further evaluated in the chemical reaction scheme. In Reaction (R17), $n=0$ (no OH-recycling). $\alpha_{1}-\alpha_{4}$ are stoichiometric coefficients, see Table 2 .

\begin{tabular}{|c|c|c|c|c|}
\hline Number & Reaction & & & Reaction rate \\
\hline R1 & $\mathrm{O}_{3}+h v$ & $\rightarrow$ & $\mathrm{O}^{1 \mathrm{D}}+\mathrm{O}_{2}$ & $6.62 \times 10^{-5} \cdot e^{-\frac{0.575}{\cos (x)}}$ \\
\hline $\mathrm{R} 2$ & $\mathrm{O}^{1 \mathrm{D}}+\mathrm{H}_{2} \mathrm{O}$ & $\rightarrow$ & $\mathrm{OH}+\mathrm{OH}$ & $1.63 \times 10^{-10} \cdot e^{\frac{60}{T}}$ \\
\hline R3 & $\mathrm{O}^{1 \mathrm{D}}+\mathrm{N}_{2}$ & $\rightarrow$ & $\mathrm{O}_{3}$ & $2.15 \times 10^{-11} \cdot e^{\frac{110}{T}}$ \\
\hline R4 & $\mathrm{O}^{1 \mathrm{D}}+\mathrm{O}_{2}$ & $\rightarrow$ & $\mathrm{O}_{3}$ & $3.30 \times 10^{-11} \cdot e^{\frac{55}{T}}$ \\
\hline R5 & $\mathrm{NO}_{2}+h v$ & $\rightarrow$ & $\mathrm{NO}+\mathrm{O}_{3}$ & $1.67 \times 10^{-2} \cdot e^{-\frac{0.575}{\cos (x)}}$ \\
\hline R6 & $\mathrm{CH}_{2} \mathrm{O}+h v$ & $\rightarrow$ & $\mathrm{HO}_{2}$ & $5.88 \times 10^{-5} \cdot e^{-\frac{0.575}{\cos (x)}}$ \\
\hline R7 & $\mathrm{OH}+\mathrm{CO}$ & $\rightarrow$ & $\mathrm{HO}_{2}+\mathrm{CO}_{2}$ & $2.40 \times 10^{-13}$ \\
\hline R8 & $\mathrm{OH}+\mathrm{CH}_{4}$ & $\rightarrow$ & $\mathrm{CH}_{3} \mathrm{O}_{2}$ & $2.45 \times 10^{-12} \cdot e^{-\frac{1775}{T}}$ \\
\hline R9 & $\mathrm{OH}+\mathrm{ISO}$ & $\rightarrow$ & $\mathrm{ISORO}_{2}$ & $1.00 \times 10^{-10}$ \\
\hline R10 & $\mathrm{OH}+\mathrm{MVK}$ & $\rightarrow$ & $\mathrm{HO}_{2}+\mathrm{CH}_{2} \mathrm{O}$ & $2.40 \times 10^{-11}$ \\
\hline R11 & $\mathrm{HO}_{2}+\mathrm{NO}$ & $\rightarrow$ & $\mathrm{OH}+\mathrm{NO}_{2}$ & $3.50 \times 10^{-12} \cdot e^{\frac{250}{T}}$ \\
\hline $\mathrm{R} 12$ & $\mathrm{CH}_{3} \mathrm{O}_{2}+\mathrm{NO}$ & $\rightarrow$ & $\mathrm{HO}_{2}+\mathrm{NO}_{2}+\mathrm{CH}_{2} \mathrm{O}$ & $2.80 \times 10^{-12} \cdot e^{\frac{300}{T}}$ \\
\hline R13 & $\mathrm{ISORO}_{2}+\mathrm{NO}$ & $\rightarrow$ & $\mathrm{HO}_{2}+\mathrm{NO}_{2}+\mathrm{CH}_{2} \mathrm{O}+\mathrm{MVK}$ & $1.00 \times 10^{-11}$ \\
\hline R14 & $\mathrm{OH}+\mathrm{CH}_{2} \mathrm{O}$ & $\rightarrow$ & $\mathrm{HO}_{2}$ & $5.50 \times 10^{-12} \cdot e^{\frac{125}{T}}$ \\
\hline R15 & $\mathrm{HO}_{2}+\mathrm{HO}_{2}$ & $\rightarrow$ & $\mathrm{H}_{2} \mathrm{O}_{2}$ & * \\
\hline R16 & $\mathrm{CH}_{3} \mathrm{O}_{2}+\mathrm{HO}_{2}$ & $\rightarrow$ & PRODUCTS & $4.10 \times 10^{-13} \cdot e^{\frac{750}{T}}$ \\
\hline R17 & $\mathrm{ISORO}_{2}+\mathrm{HO}_{2}$ & $\rightarrow$ & $n \mathrm{OH}+$ PRODUCTS & $1.50 \times 10^{-11}$ \\
\hline $\mathrm{R} 18$ & $\mathrm{OH}+\mathrm{NO}_{2}$ & $\rightarrow$ & $\mathrm{HNO}_{3}$ & $3.50 \times 10^{-12} \cdot e^{\frac{340}{T}}$ \\
\hline R19 & $\mathrm{NO}+\mathrm{O}_{3}$ & $\rightarrow$ & $\mathrm{NO}_{2}+\left(\mathrm{O}_{2}\right)$ & $3.00 \times 10^{-12} \cdot e^{-\frac{1500}{T}}$ \\
\hline R20 & $\mathrm{TERP}+\mathrm{O}_{3}$ & $\rightarrow$ & $\alpha_{1} \mathrm{C}_{1}+\alpha_{2} \mathrm{C}_{2}+\alpha_{3} \mathrm{C}_{3}+\alpha_{4} \mathrm{C}_{4}$ & $5.00 \times 10^{-16} \cdot e^{\frac{-530}{T}}$ \\
\hline $\mathrm{R} 21$ & $\mathrm{TERP}+\mathrm{OH}$ & $\rightarrow$ & $\alpha_{1} \mathrm{C}_{1}+\alpha_{2} \mathrm{C}_{2}+\alpha_{3} \mathrm{C}_{3}+\alpha_{4} \mathrm{C}_{4}$ & $1.21 \times 10^{-11} \cdot e^{\frac{436}{T}}$ \\
\hline
\end{tabular}

$* k=\left(k_{1}+k_{2}\right) \cdot k_{3} ; k_{1}=2.2 \times 10^{-13} \cdot e^{\frac{600}{T}} ; k_{2}=1.91 \times 10^{-33} \cdot e^{\frac{980}{T}} \cdot c_{\text {air }} ; k_{3}=1+1.4 \times 10^{-21} \cdot e^{\frac{2200}{T}} \cdot c_{\mathrm{H}_{2} \mathrm{O}}$

concentrations of reactive species due to the fact that the $\mathrm{BL}$ becomes higher, which increases the mixing volume, and because the air that is entrained from the FT typically contains different concentrations of reactive species. The importance of FT-BL exchange for the diurnal variability of reactants in the Amazon was already suggested by Martin et al. (1988) and Ganzeveld et al. (2008).

With respect to the surface conditions, the vegetated land surface forms the source of biogenic VOCs that are oxidized in the BL to form SOA. NO emissions from the soil influence atmospheric $\mathrm{NO}_{\mathrm{x}}$ levels and consequently the formation of the oxidants ozone $\left(\mathrm{O}_{3}\right)$ and the hydroxyl radical $(\mathrm{OH})$. In this study, we prescribe surface fluxes of sensible $(\mathrm{H})$ and latent heat (LE), VOCs and NO. The FT conditions for temperature, moisture and reactants are also imposed, both in terms of their initial value and, in the case of temperature and moisture, their lapse rate. Reactive species in the FT are affected by chemical transformations, but have an assumed constant concentration profile. More complex assumptions could be made (e.g. modification of the lapse rate of the reactants due
Table 2. Stoichiometric coefficients at $T=298 \mathrm{~K}$ for the different volatility bins of the SOA precursor category TERP, with saturation concentration $C_{i}^{*}$ in $\mu \mathrm{g} \mathrm{m}^{-3}$ from Tsimpidi et al. (2010).

\begin{tabular}{ccccc}
\hline$i$ & 1 & 2 & 3 & 4 \\
\hline$C_{i}^{*}$ & 1 & 10 & 100 & 1000 \\
$\alpha_{i}$ & 0.107 & 0.092 & 0.359 & 0.600 \\
\hline
\end{tabular}

to chemical transformations), but these would not take away the existing uncertainties, yet would increase the degrees of freedom of the model. Initial and boundary conditions are obtained from fitting MXLCH-SOA to the case study observations.

\subsection{Gas-phase chemistry}

The chemical mechanism used to represent the essentials of the $\mathrm{O}_{3}-\mathrm{NO}_{\mathrm{x}}-\mathrm{VOC}-\mathrm{HO}_{\mathrm{x}}$ chemistry is given by reactions (R1)-(R19) in Table 1. It is based on and further 
Table 3. VOC emissions for the case study. Emissions during the day follow a sinusoid with the maximum emission flux $\left(\mu \mathrm{g} \mathrm{m}^{-2} \mathrm{~h}^{-1}\right)$ as specified.

\begin{tabular}{ccc}
\hline ISO & $\alpha$-pinene & TERP \\
\hline 101 & 111 & 304 \\
\hline
\end{tabular}

extends the simplified reaction schemes used by Krol et al. (2000) and Vilà-Guerau de Arellano et al. (2011) with reaction rate coefficients from the International Union of Pure and Applied Chemistry (IUPAC) Subcommittee for Gas Kinetic Data Evaluation (http://www.iupac-kinetic.ch.cam.ac. $\mathrm{uk} /$ ). It is able to capture the essential photochemistry of the main reactive species in rural and remote areas with low anthropogenic influence. $\mathrm{O}_{3}$ deposition follows a sinusoidal profile during the day (Table 5). In this way, the deposition velocity of $\mathrm{O}_{3}$ scales with stomatal resistance and LE (e.g. Ganzeveld et al., 2008).

A simple reaction mechanism to simulate SOA formation is introduced in MXLCH. In this mechanism, semi-volatile compounds that are able to partition into the aerosol phase are generated by the first step oxidation of terpenes by $\mathrm{O}_{3}$ and $\mathrm{OH}$. Further chemical ageing is not represented. The SOA-forming reactions are shown in Table 1 (Reactions R20 and R21) and the stoichiometric coefficients in Table 2. For all simulations we assumed low $\mathrm{NO}_{\mathrm{x}}$ conditions, i.e. that organic peroxy radicals react predominantly with $\mathrm{HO}_{2}$ or $\mathrm{RO}_{2}$ and not NO, which is a reasonable approximation for the conditions of our study.

All terpenes in our model are assumed to behave as $\alpha$ pinene with reaction rate coefficients from Atkinson and Arey (2003). The total terpene concentration is the sum of the measured concentrations of 8 terpenes by Spirig et al. (2004). In the experiments, we used TERP, a generic terpene with the properties of $\alpha$-pinene, but with emissions scaled up to reproduce the total terpene concentration. Hao et al. (2011) showed that for low VOC concentrations $\left(<5 \mu \mathrm{g} \mathrm{m}^{-3}\right)$ the assumption that SOA yields for $\alpha$-pinene and real plant emissions are similar is justified. Furthermore, we assumed that aerosol yields from $\alpha$-pinene with $\mathrm{OH}$ are equal to the better documented yields for ozonolysis of $\alpha$-pinene. The information on $\mathrm{OH}$ initiated oxidation in the literature is limited. Hao et al. (2011) reported a higher volatility and thus lower yields from $\mathrm{OH}$ dominated chemistry than for $\mathrm{O}_{3}$ initiated oxidation. In contrast, there are other experiments which show that $\mathrm{OH}$ yields are a little higher than the $\mathrm{O}_{3}$ yields $(\mathrm{N}$. Donahue, personal communication, 2011; Henry and Donahue, 2011). Finally, we assumed that aerosol formation from isoprene can be neglected due to the low concentrations of this precursor at our study location (e.g. Spirig et al., 2004).

Terpene emissions are prescribed with a sinusoidal profile during the day with a maximum as specified in Table 3. The sinusoidal form of the diurnal emission is supported by the terpene flux measurements of Rinne et al. (2007). The prescribed terpene fluxes lie within the range of the measurements by Rinne et al. (2007) for similar temperatures and at the same location, but are higher than the estimates for the same dataset with the mixed layer gradient method by Spirig et al. (2004). One reason for this discrepancy could be the fact that the method used by Spirig et al. (2004) did not account for entrainment and therefore underestimates dilution of the terpenes in the BL.

\subsection{Organic aerosol formation: gas/particle partitioning}

Gas/particle partitioning is dominated by absorption of semivolatile species into an organic aerosol phase (Pankow, 1994). We assume that the semi-volatile terpene oxidation products are in thermodynamic equilibrium with the aerosol phase, which means that partitioning occurs instantaneously. We account for gas/particle partitioning in MXLCH-SOA by implementing the volatility basis set approach (Donahue et al., 2006). This approach lumps the numerous semivolatile products that are formed after VOC oxidation into several bins with logarithmically spaced effective saturation concentrations. The mass yields for the different bins are obtained by fitting results from laboratory studies of SOA formation. Here, we use 4 bins with effective saturation concentrations of $1,10,100$ and $1000 \mu^{-3} \mathrm{~m}^{-3}$ at $298 \mathrm{~K}$, encompassing a relevant range of product vapor pressures (Lane et al., 2008). The mass stoichiometric coefficients for the different bins of the TERP category of the SOA precursors are taken from Tsimpidi et al. (2010), see Table 2. At each time step, the total organic aerosol concentration $C_{\mathrm{OA}}$ is diagnosed from:

$C_{\mathrm{OA}}=\sum_{i}\left(X_{p, i} C_{i}\right)+\mathrm{OA}_{\mathrm{BG}} ; \quad X_{p, i}=\left(1+\frac{C_{i}^{*}}{C_{\mathrm{OA}}}\right)^{-1}$

where $C_{\mathrm{OA}}$ is the total organic aerosol mass concentration $\left(\mu \mathrm{g} \mathrm{m}^{-3}\right), \mathrm{OA}_{\mathrm{BG}}$ the background organic aerosol concentration $\left(\mu \mathrm{g} \mathrm{m}^{-3}\right), X_{p, i}$ is the fraction of compound $i$ in the aerosol phase (dimensionless), and $C_{i}^{*}$ is the effective saturation concentration of compound $i\left(\mu \mathrm{g} \mathrm{m}^{-3}\right)$.

Temperature dependence of the saturation concentrations follows Clausius-Clapeyron (Sheehan and Bowman, 2001):

$C_{i}^{*}=C_{i, 0}^{*} \frac{T_{0}}{T} \exp \left[\frac{\Delta H_{\mathrm{vap}}}{R}\left(\frac{1}{T_{0}}-\frac{1}{T}\right)\right]$

in which $C_{i, 0}^{*}$ is the effective saturation concentration of compound $i$ at reference temperature $T_{0}$ (here $298 \mathrm{~K}$ ), $T$ is the actual temperature $(\mathrm{K}), \Delta H_{\mathrm{vap}}$ is the enthalpy of vaporization $\left(\mathrm{kJ} \mathrm{mol}^{-1}\right)$, and $R$ is the ideal gas constant $\left(\mathrm{J} \mathrm{mol}^{-1} \mathrm{~K}^{-1}\right)$. Here, we follow Pathak et al. (2007) and set $\Delta H_{\mathrm{vap}}$ to $30 \mathrm{~kJ} \mathrm{~mol}^{-1}$ for all condensable products. 


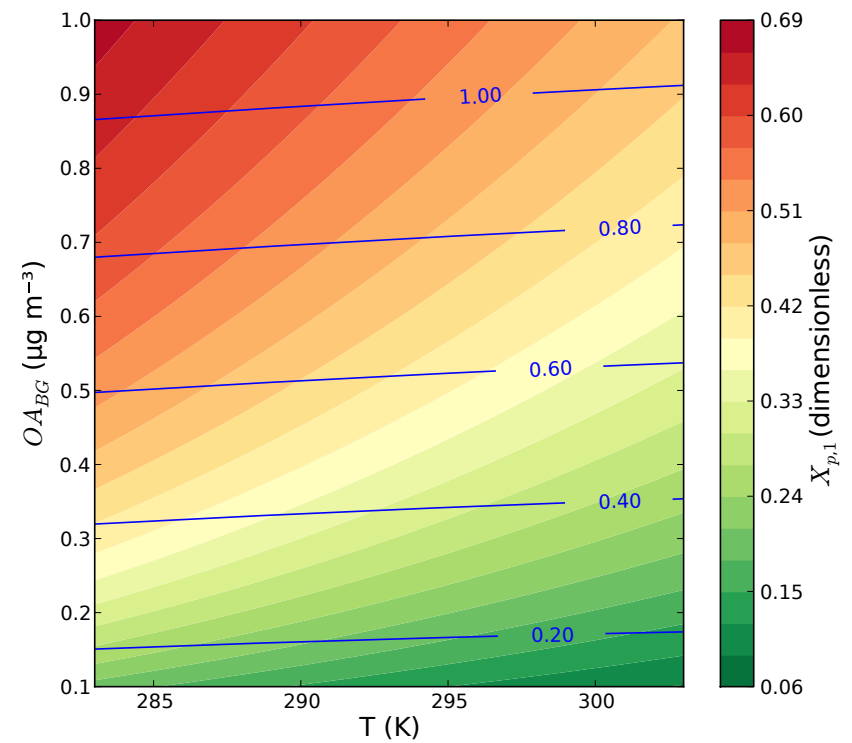

Fig. 2. Sensitivity of the partitioning coefficient of the first bin $\left(X_{p, 1}\right)$ and organic aerosol concentration $\left(C_{\mathrm{OA}}\right)$ to temperature $(T)$ and the background organic aerosol concentration $\left(\mathrm{OA}_{\mathrm{BG}}\right)$. Shades indicate $X_{p, 1}$ (dimensionless) and the blue contours $C_{\mathrm{OA}}\left(\mu \mathrm{g} \mathrm{m}^{-3}\right)$.

A background $C_{\mathrm{OA}}$ of $0.8 \mu \mathrm{g} \mathrm{m}^{-3}$ and of $0.2 \mu \mathrm{g} \mathrm{m}^{-3}$ is assumed for the BL and FT, respectively. The BL value is based on the measurements by Raatikainen et al. (2010). These measurements are made in the canopy and therefore serve as an estimate of the order of magnitude for the BL concentration. Since a FT value is not available from measurements, we have performed an analysis to determine the sensitivity to the assumed value, presented in Sect. 3.2. The background organic aerosol in BL and FT is assumed to be aged and thus non-volatile, and will therefore not repartition back into the gas phase (Cappa and Jimenez, 2010).

Figure 2 shows the sensitivity of the calculated partitioning coefficient for the first bin $\left(X_{p, 1}\right)$ and $C_{\mathrm{OA}}$ to variations in $T$ and $\mathrm{OA}_{\mathrm{BG}}$ for a range of typical values for this study. While the response of $X_{p, 1}$ to variations in $T$ and $\mathrm{OA}_{\mathrm{BG}}$ is quite nonlinear, especially at low $T$ and high $\mathrm{OA}_{\mathrm{BG}}$, the response of $C_{\mathrm{OA}}$ is nearly linear to changes in $\mathrm{OA}_{\mathrm{BG}}$. This is due to the fact that the strongest nonlinear behavior of $X_{p, 1}$ is found for conditions where $\mathrm{OA}_{\mathrm{BG}}$ makes up the largest part of $C_{\mathrm{OA}}$, and therefore the partitioning of semi-volatile species $C_{1}$ into the aerosol phase plays only a minor role in determining $C_{\mathrm{OA}}$. The sensitivities of the partitioning coefficients of the other bins show similar patterns.

\subsection{Observational evaluation: case study}

To evaluate our modeling approach, we selected a dataset of surface and boundary layer characteristics (both dynamics and chemistry) that is as complete as possible. Our assumption of a well-mixed boundary layer is justified for sunny days characterized by convective turbulent conditions. To
Table 4. The initial and boundary conditions in boundary layer (BL) and free troposphere (FT) as obtained from fitting MXLCH-SOA to the case study observations. All initial conditions are imposed at 07:50 LT. Heat fluxes are applied from 07:50 to 18:50 LT with $\mathrm{H}=$ $\rho c_{p} \overline{w^{\prime} \theta^{\prime}}$ s and LE $=\rho L_{\mathrm{V}} \overline{w^{\prime} q_{\mathrm{s}}^{\prime}}$. $t$ is the time (s) and $t_{d}$ the length of the simulation (s). The subscripts $s$ and $e$ indicate values at the surface and the entrainment zone, respectively.

\begin{tabular}{|c|c|}
\hline Property & Value \\
\hline $\begin{array}{l}\text { Initial BL height } \\
\quad h(\mathrm{~m})\end{array}$ & 200 \\
\hline $\begin{array}{l}\text { Subsidence rate } \\
\qquad \omega\left(\mathrm{s}^{-1}\right)\end{array}$ & 0 \\
\hline $\begin{array}{l}\text { Surface sensible heat flux } \\
\overline{w^{\prime} \theta_{\mathrm{S}}^{\prime}}\left(\mathrm{Kms}^{-1}\right)\end{array}$ & $0.11 \sin \left(\pi t / t_{d}\right)$ \\
\hline $\begin{array}{l}\text { Entrainment/surface heat flux ratio } \\
\qquad \beta=-\overline{w^{\prime} \theta^{\prime}} \mathrm{e} / \overline{w^{\prime} \theta^{\prime}}{ }_{\mathrm{s}} \text { (dimensionless) }\end{array}$ & 0.2 \\
\hline $\begin{array}{l}\text { Initial BL potential temperature } \\
\langle\theta \theta(\mathrm{K})\end{array}$ & 288 \\
\hline $\begin{array}{l}\text { Initial FT potential temperature } \\
\theta_{\mathrm{FT}}(\mathrm{K})\end{array}$ & 288.4 \\
\hline $\begin{array}{l}\text { Potential temperature lapse rate FT } \\
\qquad \gamma_{\theta}\left(\mathrm{Km}^{-1}\right)\end{array}$ & 0.0035 \\
\hline $\begin{array}{l}\text { Surface latent heat flux } \\
\overline{w^{\prime} q_{\mathrm{s}}^{\prime}}\left(\mathrm{g} \mathrm{kg}^{-1} \mathrm{~ms}^{-1}\right)\end{array}$ & $0.06 \sin \left(\pi t / t_{d}\right)$ \\
\hline $\begin{array}{l}\text { Initial BL specific humidity } \\
\quad\langle q\rangle\left(\mathrm{g} \mathrm{kg}^{-1}\right)\end{array}$ & 8.0 \\
\hline $\begin{array}{l}\text { Initial FT specific humidity } \\
\quad q_{\mathrm{FT}}\left(\mathrm{g} \mathrm{kg}^{-1}\right)\end{array}$ & 6.25 \\
\hline $\begin{array}{l}\text { Specific humidity lapse rate FT } \\
\quad \gamma_{\mathrm{q}}\left(\mathrm{g} \mathrm{kg}^{-1} \mathrm{~m}^{-1}\right)\end{array}$ & -0.0024 \\
\hline
\end{tabular}

meet these two requirements, we selected observations from 8 August 2001 at the SMEAR II field station at Hyytiälä $\left(61^{\circ} 51^{\prime} \mathrm{N}, 24^{\circ} 17^{\prime} \mathrm{E}\right)$ in southern Finland, where ecosystem, meteorological, trace gas and aerosol properties have been measured since 1996 (Hari and Kulmala, 2005).

Surface fluxes of sensible (H) and latent heat (LE) are measured at $23.3 \mathrm{~m}$ by means of the eddy covariance technique (Mammarella et al., 2009). These observations are used as forcing for our model and are therefore prescribed as boundary conditions. The model simulation covers $11 \mathrm{~h}$, beginning at 07:50 LT (sunrise is at 07:30 LT). The diurnal evolution of temperature, humidity, $\mathrm{O}_{3}$ and $\mathrm{NO}_{\mathrm{x}}$, observed at $67.2 \mathrm{~m}$ - the highest measurement level available at $52 \mathrm{~m}$ above the canopy - and obtained using the SMEAR SmartSearch database (Junninen et al., 2009), is used to determine the ability of the model to reproduce the diurnal variability in the BL. In addition, observations of BL height from temperature and humidity profiles and BL concentrations of terpenes gathered with a tethered balloon (Spirig et al., 2004) enable us to complete the validation. 

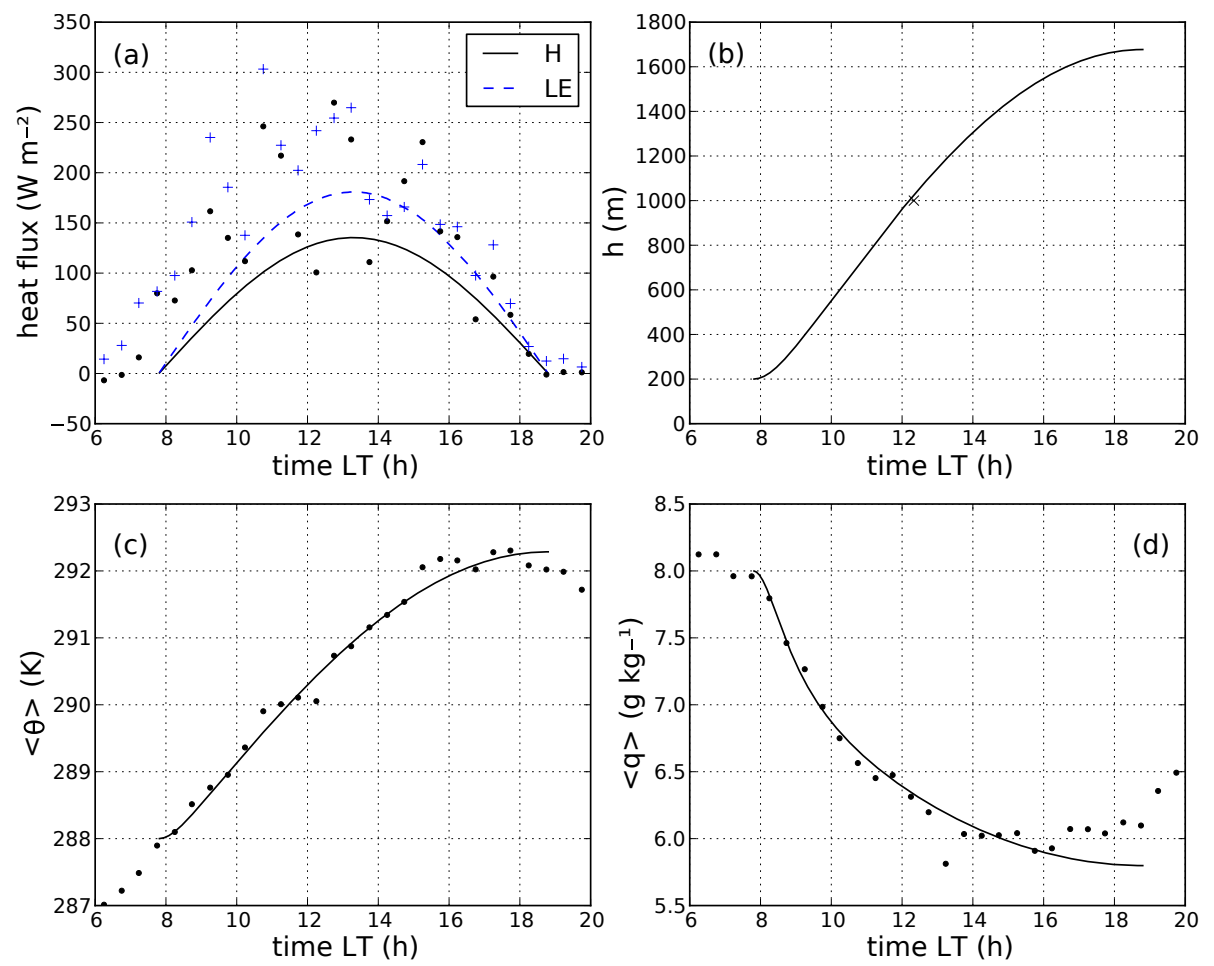

Fig. 3. Diurnal evolution of (a) surface sensible (H) and latent (LE) heat flux, which are both prescribed, (b) boundary layer height $(h)$, (c) mixed layer potential temperature $(\langle\theta\rangle)$ and (d) mixed layer specific moisture $(\langle q\rangle)$ for the case study. Dots and crosses indicate tower (at $67.2 \mathrm{~m})$ and balloon measurements, respectively. Model results are indicated by lines.

\subsection{Numerical strategy}

We designed a series of numerical experiments to investigate the dependence of the SOA evolution on the chemical and dynamical processes and their relationships as depicted in Fig. 1. In the first experiment, we study the sensitivity of $C_{\mathrm{OA}}$ to the surface conditions. The sensitivity analysis is carried out as a function of the evaporative fraction (EF) and the terpene emission flux ( $F_{\text {TERP }}$ ) (indicated by (1) in Fig. 1$)$. EF is defined as $\mathrm{LE} /(\mathrm{H}+\mathrm{LE})$, i.e. it is the fraction of the surface heat flux that is used for evaporation of water from the surface. In the second experiment, we evaluated the sensitivity of $C_{\mathrm{OA}}$ to $\mathrm{EF}$ and to large-scale vertical subsidence motions (indicated by (2) in Fig. 1). The latter are due to the presence of synoptic high pressure systems that suppress the BL growth. In these analyses, we studied $C_{\mathrm{OA}}$ at the end of the day (18:50), because then BL growth and entrainment cease and we can evaluate the net effect of the daytime dynamics, emissions and chemistry.

\section{Results}

\subsection{Model evaluation}

Figure 3 shows the time evolution of the dynamic variables for the initial and boundary conditions as specified in Table 4 : the surface heat fluxes (H and LE), boundary layer height $(h)$, mixed layer potential temperature $(\langle\theta\rangle)$ and specific moisture $(\langle q\rangle)$. The onset of the prescribed surface heat fluxes is delayed by about one hour, as compared to the measurements. By so doing, we ensure that the model calculations begin within the well-mixed assumptions when the ground thermal inversion is already broken. Both $\mathrm{H}$ and LE fall within the low end of the observations. This results from fitting the model to observed $\theta, q$ and $h$ and could be due to the different footprints of the heat fluxes and $\theta$ and $q: \mathrm{H}$ and LE are measured at $23.3 \mathrm{~m}$, while $\theta$ and $q$ are observed at $67.2 \mathrm{~m}$, and consequently the measurements of $\mathrm{H}$ and LE represent a smaller area.

The time evolutions of $\langle\theta\rangle$ and $\langle q\rangle$ are reproduced well. This satisfactory agreement of the $\langle\theta\rangle$ and $\langle q\rangle$ evolutions demonstrates that the model is capable of reproducing the entrainment process well for a given set of surface heat fluxes. Although only one observation is available at 12:20, the calculated BL height is similar to the measured height of $1000 \mathrm{~m}$.

The diurnal trends in the chemical species (Fig. 4), with initial concentrations and surface fluxes as specified in Table 5, agree well with the observations. This confirms that the processes of entrainment, emission and chemistry (see Fig. 1) and their influence on the time evolution of the chemical species are simulated well. The evolution of $\mathrm{O}_{3}$ is the 
Table 5. Initial mixing ratios in BL and FT and surface emission fluxes of the reactants as obtained from fitting MXLCH-SOA to the case study observations. Species in the reaction mechanism that are not included in this table have zero initial concentrations and zero surface emissions, except TERP and ISO (see Table 3). For the molecules $\mathrm{O}_{2}$ and $\mathrm{N}_{2}$, we have imposed the values $2 \times 10^{8}$ and $8 \times 10^{8}$ ppb, respectively.

\begin{tabular}{lccccc}
\hline & $\mathrm{O}_{3}$ & $\mathrm{NO}$ & $\mathrm{NO}_{2}$ & $\mathrm{CH}_{4}$ & $\mathrm{CO}$ \\
\hline Initial mixing ratio $(\mathrm{ppb})$ & & & & & \\
$\quad$ BL & 31.0 & 0.04 & 0.1 & 1800. & 100. \\
FT & 39.0 & 0.0 & 0.2 & 1800. & 100. \\
Surface emission flux $\left(\mathrm{ppbm} \mathrm{s}^{-1}\right)$ & $-0.20 \sin \left(\frac{\pi t}{t_{d}}\right)$ & $4 \times 10^{-3}$ & 0.0 & 0.0 & 0.0 \\
\hline
\end{tabular}
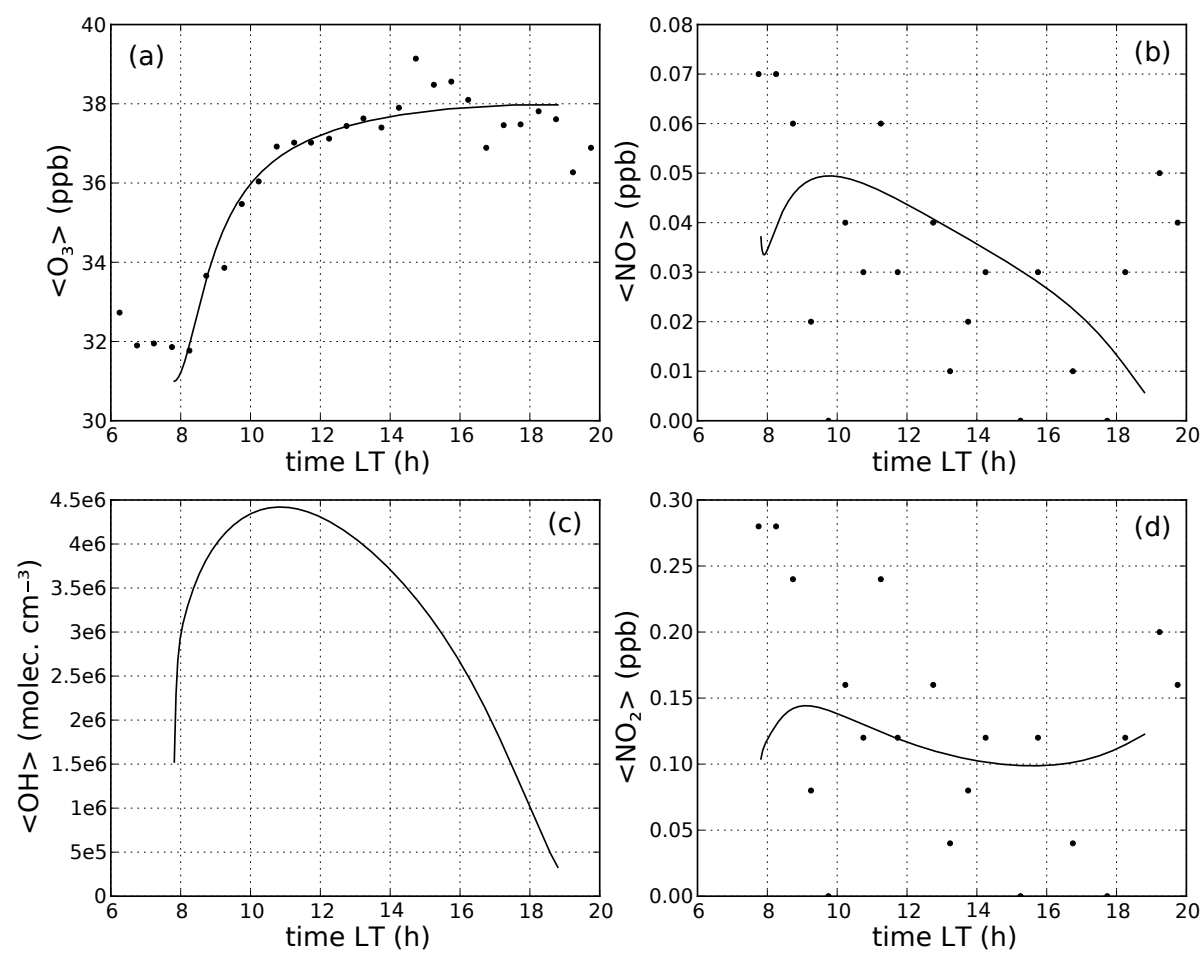

Fig. 4. Diurnal evolution of mixed layer concentrations of (a) $\mathrm{O}_{3}$, (b) $\mathrm{NO}$, (c) $\mathrm{OH}$ and (d) $\mathrm{NO}_{2}$ for the case study. $\mathrm{NO}_{2}$ measurements are scaled down to match the $\mathrm{NO}_{2} / \mathrm{NO}$ ratio of 5 obtained during summer 2010 from more reliable measurements than those from August 2001 . Dots indicate measurements from the tower at $67.2 \mathrm{~m}$. Model results are indicated by lines.

result of entrainment of $\mathrm{O}_{3}$ from the $\mathrm{FT}$, especially during the rapid growth of the BL during the morning, a net positive chemical production during the day and its removal by dry deposition. Averaged over the day, the entrainment flux is about 1.4 times as large as the deposition flux, but in the early morning (08:00) the entrainment flux is 8 times larger than the deposition flux. This is due to the fact that the $\mathrm{O}_{3}$ deposition flux follows a sinusoidal form during the day (Table 5), which has a minimum in the morning. The $\mathrm{NO}_{\mathrm{x}}$ measurements must be interpreted carefully since they are probably affected by error in the measurement procedure (P. Keronen, personal communication, 2011). Possible sources of error are the absence of a $\mathrm{NO}_{2}$ specific converter in the $\mathrm{NO}_{\mathrm{x}}$ analyser, which may have biased the observed $\mathrm{NO}_{2}$ concentration upwards, and the $100 \mathrm{~m}$ sampling line, which may have affected the observed $\mathrm{NO}$ concentrations. $\mathrm{NO}_{2}$ measurements are scaled down to match an observed $\mathrm{NO}_{2} / \mathrm{NO}$ ratio of 5 as obtained from more reliable measurements in summer 2010 at the same location (P. Keronen, personal communication, 2011). In spite of the large uncertainty regarding the $\mathrm{NO}_{\mathrm{x}}$ measurements, we are able to satisfactorily reproduce the order of magnitude of the observed $\mathrm{NO}_{\mathrm{x}}$ concentrations. Calculated $\mathrm{OH}$ concentrations range from $4 \times 10^{5}$ at the end of the day to $4.5 \times 10^{6}$ molec $\mathrm{cm}^{-3}$ in the late morning. Unfortunately, no observations of $\mathrm{OH}$ in the mixed layer (above the canopy) are available for this environment. Petäjä et al. (2009) report an observed diurnal range in in-canopy $\mathrm{OH}$ concentrations in the order of $10^{4}$ to $10^{5}$ molec $\mathrm{cm}^{-3}$. BL 

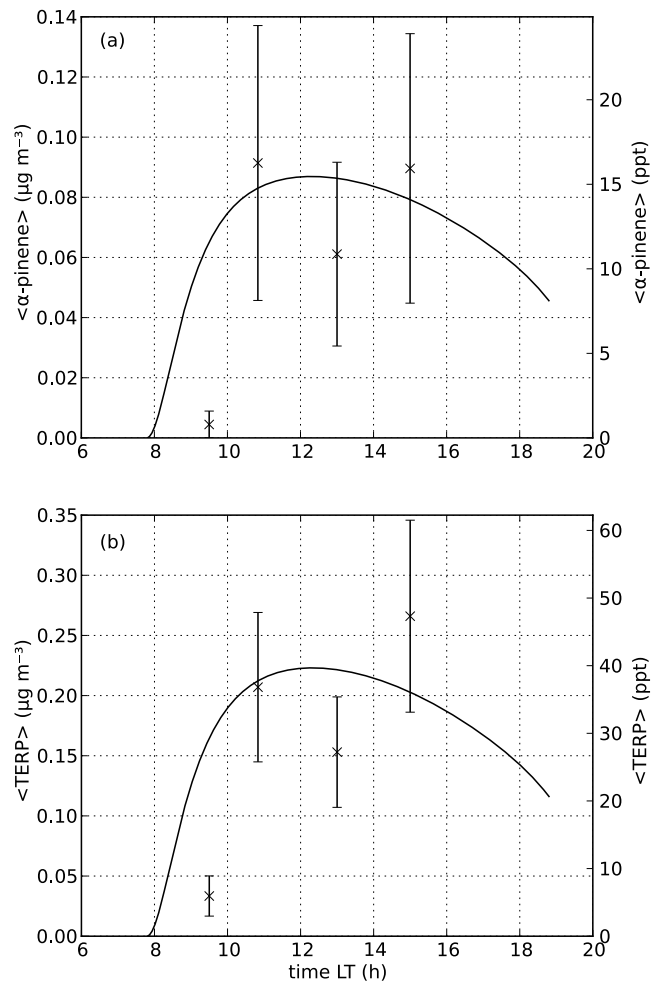

Fig. 5. (a) $\langle\alpha$-pinene $\rangle$ and (b) sum of terpenes ( $\langle$ TERP $\rangle)$ for the case study. Crosses indicate balloon measurements and model results are indicated by lines. Errors are $100 \%$ for concentrations lower than $0.03 \mu \mathrm{g} \mathrm{m}^{-3}, 50 \%$ for concentrations between 0.03 and $0.15 \mu \mathrm{g} \mathrm{m}^{-3}$ and $30 \%$ for concentrations higher than $0.15 \mu \mathrm{g} \mathrm{m}^{-3}$. The conversion factor from $\mu \mathrm{g} \mathrm{m}^{-3}$ to ppt is 178 .

concentrations are likely higher, because of the higher $\mathrm{O}_{3}$ concentration and light intensity and lower concentrations of VOCs, which deplete $\mathrm{OH}$. We find, however, that $C_{\mathrm{OA}}$ is not very sensitive to $\mathrm{OH}$ levels. For the case study, increasing the $\mathrm{OH}$ concentration by a factor 2 resulted in an increase of $C_{\mathrm{OA}}$ at the end of the day of only $1 \%$ and reducing it by a factor 2 in a decrease of $3 \%$. The reason for this weak sensitivity will be further discussed in Sect. 3.3.

Figure 5 shows the results for terpenes with emission fluxes as specified in Table 3. MXLCH-SOA is able to reproduce the order of magnitude of the observed concentrations of both $\alpha$-pinene and the sum of terpenes ( $(T E R P\rangle)$. Since there are only four data points and the error in the individual measurements is large, we cannot draw conclusions on how well we can reproduce the diurnal evolution of the terpene concentrations from these data. Typically, terpene concentrations will increase during nighttime (e.g. Ruuskanen et al., 2009) due to temperature-driven emissions into a BL that is shallow and stably stratified. Besides, it is characterized by low $\mathrm{O}_{3}$ concentrations and consequently low chemical destruction. A sensitivity analysis revealed that the diurnal cy-

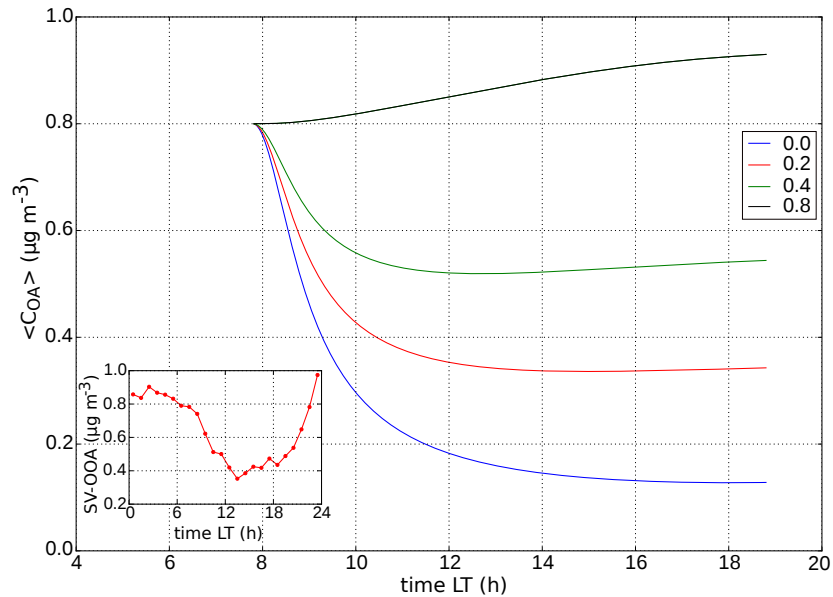

Fig. 6. Organic aerosol concentration $C_{\mathrm{OA}}$ for the case study, including the sensitivity to different FT background OA concentrations $\left(0.0,0.2,0.4,0.8 \mu \mathrm{g} \mathrm{m}^{-3}\right)$. The inset shows the diurnal cycle of the measured SV-OOA-concentration, averaged over 15 days.

cle in $C_{\mathrm{OA}}$ is not very sensitive to the initial terpene concentration. The reason for this will be discussed further in Sect. 3.3.

Overall, comparison of the model results with the observations shows that we can reproduce the time evolution of the dynamics and the order of magnitude of the gas-phase chemistry well, which gives confidence in the validity of MXLCHSOA for further analyses.

\subsection{Diurnal evolution of organic aerosol}

A key aspect of this study is the ability of MXLCH-SOA to model the organic aerosol concentration $C_{\mathrm{OA}}$ as a function of dynamics and chemistry (Fig. 1). As expressed in Eq. (1), the background organic aerosol concentration $\mathrm{OA}_{\mathrm{BG}}$ affects $C_{\mathrm{OA}}$ both directly and indirectly by influencing the partitioning into the aerosol phase of the semi-volatile reaction products $\left(C_{i}\right)$ that result from TERP oxidation. Therefore, to understand the diurnal evolution of $C_{\mathrm{OA}}$ it is crucial to represent the $\mathrm{OA}_{\mathrm{BG}}$ accurately, both in the $\mathrm{BL}$ and the FT, the latter since $\mathrm{OA}_{\mathrm{BG}}$ from the $\mathrm{FT}$ is entrained into the $\mathrm{BL}$ during its growth.

Unfortunately, there are no observed vertical $C_{\mathrm{OA}}$ profiles for this environment, which could help constrain our numerical experiments (Heald et al., 2011). In order to determine the sensitivity of the diurnal cycle in $C_{\mathrm{OA}}$ to the FT $\mathrm{OA}_{\mathrm{BG}}$, we carry out 4 identical numerical experiments, only varying the $\mathrm{OA}_{\mathrm{BG}}$ in the FT (Fig. 6). By so doing, we are able to study the influence of the $\mathrm{OA}_{\mathrm{BG}}$ in the residual layer (the remainder of the $\mathrm{BL}$ from the previous day) that was decoupled from the nocturnal boundary layer. We included a case for which BL and FT concentrations are equal. This may not be realistic, because we simulate biogenic OA only, which has a surface source and thus lower concentrations in the FT; however, the 
high FT biogenic OA is shown for illustrational purposes. Since we expect that $C_{\mathrm{OA}}$ is much lower in the FT than in the BL, the other three cases represent FT OA $\mathrm{BG}_{\mathrm{BG}}$ of $0.0,0.2$ and $0.4 \mu \mathrm{g} \mathrm{m}^{-3}$. For all these cases, we find a net decrease of $C_{\mathrm{OA}}$ during the day. Without further observational constraints on the actual FT concentration, we assumed a value of $0.2 \mu \mathrm{g} \mathrm{m}^{-3}$ for the numerical experiments presented hereafter.

There are only a few measurements of organic aerosol concentrations for the location of our case study, and as a result we are not able to directly compare modeled with measured data. There are, however, observations available at the same site that allow us to qualitatively compare the diurnal behavior of OA. Raatikainen et al. (2010) measured organic aerosol concentrations at Hyytiälä during 15 days in spring 2005. They identified two oxygenated organic aerosol (OOA) groups. One of them, SV-OOA (semi-volatile OOA, formally OOA2), has a clear diurnal cycle, has undergone little oxidation and is qualified as originating from local sources, the most likely being the oxidation of locally emitted VOCs based on the observation that the presence of SV-OOA is independent of air mass history. Therefore, it is interesting to compare the diurnal cycle of SV-OOA with the simulated $C_{\mathrm{OA}}$ and we include the SV-OOA data in Fig. 6. The measured SV-OOA shows a similar concentration decrease during the day as the modeled $C_{\mathrm{OA}}$. This further indicates the need to have a balanced approach in calculating the $C_{\mathrm{OA}}$ taking into account emission, dynamical processes like entrainment and chemical transformations (Fig. 1). The absolute concentrations should be compared with care, however, since the measurements were performed inside the canopy while the model results reflect BL averages.

\subsection{Budgets}

To deepen our understanding of the concentration tendencies, we make use of the ability of the mixed layer model to calculate the different contributions of entrainment, emissions and chemistry to the total tendency of chemical species (Tennekes, 1973; Vilà-Guerau de Arellano et al., 2011), in this case $C_{\mathrm{OA}}$ and TERP. The TERP budget reads:

$$
\begin{aligned}
& \frac{\mathrm{d}\langle\text { TERP }\rangle}{\mathrm{d} t}=\overbrace{\frac{F_{\text {TERP }}}{h} \sin \left(\frac{\pi t}{t_{d}}\right)}^{\text {emission }}+\overbrace{\frac{w_{\mathrm{e}} \Delta \mathrm{TERP}}{h}}^{\text {entrainment }} \\
& -\overbrace{\sum_{j} k_{j}\langle\mathrm{TERP}\rangle\left\langle\mathrm{OX}_{j}\right\rangle}^{\text {chemistry }}
\end{aligned}
$$

where $F_{\mathrm{TERP}}$ is the maximum daily terpene emission flux $\left(\mu \mathrm{g} \mathrm{m}^{-2} \mathrm{~h}^{-1}\right)$, as specified in Table $3 ; h$ is the BL height $(\mathrm{m})$; $t$ is the time since the start of the simulation (s); $t_{d}$ is the length of the simulation (s); $w_{\mathrm{e}}$ is the entrainment velocity $\left(\mathrm{m} \mathrm{s}^{-1}\right)$, which in absence of subsidence equals BL growth $(\mathrm{d} h / \mathrm{d} t) ; \Delta$ TERP is the TERP concentration jump between
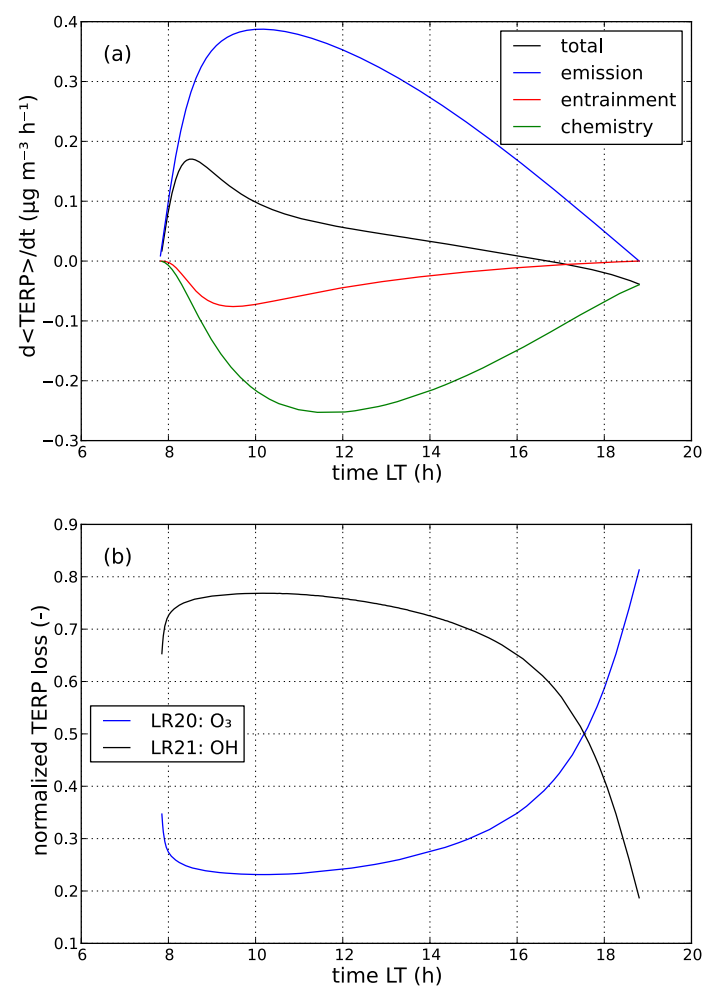

Fig. 7. Contribution of the individual processes to the terpene tendency (Eq. 3) for the case study. (a) total tendency and the individual contributions of emission, entrainment and chemistry, and (b) the normalized contributions to the chemical terpene loss for the reactions with $\mathrm{O}_{3}$ and $\mathrm{OH}$.

the BL and the FT $\left(\mu \mathrm{g} \mathrm{m}^{-3}\right)$ (with the jump of a scalar or reactant $C$ defined as $\Delta C=C_{\mathrm{FT}}-\langle C\rangle$, see also Fig. 10); $k_{j}$ is the reaction rate of TERP with oxidant $\mathrm{OX}_{\mathrm{j}}$ (either $\mathrm{O}_{3}$ or $\mathrm{OH})$; and $\left\langle\mathrm{OX}_{j}\right\rangle$ is the mixed layer concentration of oxidant $\mathrm{OX}_{\mathrm{j}}$. Note that $h, w_{\mathrm{e}}, \Delta \mathrm{TERP},\langle\mathrm{TERP}\rangle$ and $\langle\mathrm{OX}\rangle$ are calculated simultaneously during the MXLCH-SOA runs and therefore account for the coupling between dynamics and chemistry. This defines the difference between our approach and using box models with a fixed $h$ or a BL growth calculated from measurements: here, the development of the BL and entrainment are governed by the diurnal dynamics of temperature and moisture, through $w_{\mathrm{e}}$ in the second term on the right hand side (RHS) of Eq. (3), which result from the coupling of the BL with the land surface and the FT.

Figure 7 shows the budget of TERP and the relative contributions to the total chemical tendency of the reactions of TERP with $\mathrm{O}_{3}$ and $\mathrm{OH}$ for the case study. Overall, emission and chemistry contribute about equally to the budget (Fig. 7a). The prescribed $F_{\text {TERP }}$ is low in the early morning, but since the BL is still shallow, the emission term contributes strongly to the TERP budget during the course of the morning and becomes the most important term with a maximum of $0.4 \mu \mathrm{g} \mathrm{m}^{-3} \mathrm{~h}^{-1}$ at 10:00. After this time, the BL height increases rapidly, which decreases the importance of 
this term. The chemistry is dominated by the destruction by $\mathrm{OH}$ (Fig. 7b), so the late morning peak in the chemistry term is associated with the peak in $\mathrm{OH}$ that occurs then. The contribution of $\mathrm{O}_{3}$ to the chemical destruction of TERP is $25 \%$ during the day, but becomes dominant in the evening as $\mathrm{OH}$ is reduced. Entrainment contributes significantly to the total tendency between 9 and 12 when BL growth is strongest with $230 \mathrm{~m} \mathrm{~h}^{-1}$. The maximum contribution of entrainment to the total tendency of TERP is about $20 \%$ of the contribution of the emission. During most of the morning, the TERP tendency is positive, mainly due to the emissions, but at the end of the afternoon the tendency becomes negative due to the fact that chemical destruction continues while the emissions decrease.

Damköhler numbers (the ratio of the turbulent time scale to the chemistry time scale) for TERP range from 0.05 to 0.2 . Under this regime of relatively slow chemistry, the emission and entrainment (term 1 and 2 on the RHS of Eq. 3) play an important role. This further confirms the importance of the atmospheric transport and turbulence for the behavior of TERP.

Similar to Eq. (3) for TERP, we can calculate the budget of $C_{\mathrm{OA}}$. The derivation of the $C_{\mathrm{OA}}$ budget is more complex than that of TERP, so here we show an approximation which is accurate under the conditions of this study (the full derivation is given in Appendix A):

$$
\begin{aligned}
& \frac{\mathrm{d} C_{\mathrm{OA}}}{\mathrm{d} t} \simeq \frac{\overbrace{w_{\mathrm{e}} \Delta \mathrm{OA}_{\mathrm{BG}}}^{\mathrm{OA}_{\mathrm{BG}} \text {-entrainment }}}{h} \\
& +\sum_{i} X_{p, i}[\overbrace{\frac{w_{\mathrm{e}} \Delta C_{i}}{h}}^{C_{i} \text {-entrainment }}+\overbrace{\sum_{j} \alpha_{i} k_{j}\langle\mathrm{TERP}\rangle\left\langle\mathrm{OX}_{j}\right\rangle}^{C_{i} \text {-chemistry }}] .
\end{aligned}
$$

Here, $\triangle \mathrm{OA}_{\mathrm{BG}}$ is the jump in the background organic aerosol concentration between the BL and the FT $\left(\mu \mathrm{g} \mathrm{m}^{-3}\right), \Delta \mathrm{C}_{\mathrm{i}}$ the concentration jump of the oxidized semivolatile product $C_{i}$, and $\alpha_{i}$ the stoichiometric coefficient for $C_{i}$ (see Table 2).

Note that for the $C_{\mathrm{OA}}$ budget, contrary to the TERP budget, there is no emission term since the aerosol is either of secondary origin or present as a background concentration. This is justified since our budget is focused on the submicron OA concentrations, while primary biological particles (PBAP) are thought to be important only for the supermicron mode (Pöschl et al., 2010).

The evolution of $C_{\mathrm{OA}}$ is thus the result of a combination of the influence of the $\mathrm{OA}_{\mathrm{BG}}$ originating from the FT and the newly formed condensable species from the oxidation of TERP (Fig. 5b). Entrainment of background OA dominates the budget of $C_{\mathrm{OA}}$ (Fig. 8): during the morning, the OA that was concentrated in the shallow BL during the night is diluted when the BL grows and air from the FT with a lower $\mathrm{OA}_{\mathrm{BG}}$ concentration is entrained. The importance in our simulations of the background OA level in the FT stresses the

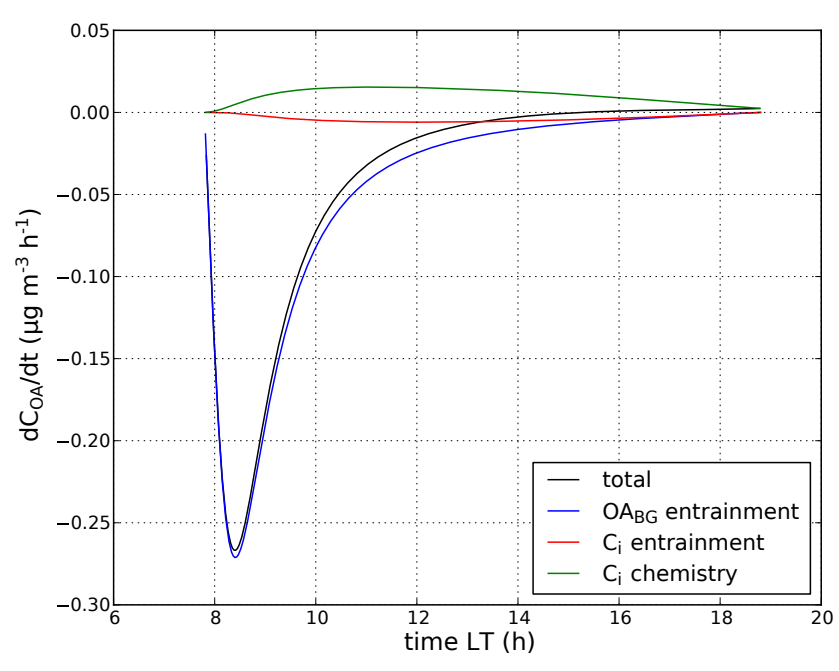

Fig. 8. Organic aerosol tendency (Eq. 4) for the case study. Shown are the total tendency and the contributions of the entrainment of background organic aerosol $\left(\mathrm{OA}_{\mathrm{BG}}\right)$, the entrainment of condensable products from terpene oxidation $\left(C_{i}\right)$, and the chemical production of $C_{i}$ to the tendency.

importance of having upper air measurements (Heald et al., 2011) to understand the evolution of $C_{\mathrm{OA}}$ in the BL. The semi-volatile products $C_{i}$ have net production throughout the day, but their contribution to the $C_{\mathrm{OA}}$ budget is relatively small. Only at the end of the day (from 15:30 onwards) is there a net positive tendency of $C_{\mathrm{OA}}$, since the $\mathrm{BL}$ growth becomes negligible and the partitioning of terpene $C_{i}$ to the particle phase outweighs the entrainment term.

These tendencies show that for TERP and $C_{\mathrm{OA}}$ emissions, chemistry and entrainment play a different role, which is important in understanding the results of the sensitivity analyses, presented in Sect. 3.4. Since TERP is a reactive species with a relatively short lifetime and no background concentration, the relative importance of chemistry in its budget is larger than for OA, which does have a long lived background with a typical lifetime of a week.

To quantify the importance of the newly formed SOA from TERP oxidation $\left(\mathrm{OA}_{\mathrm{TERP}}\right)$ versus the $\mathrm{OA}_{\mathrm{BG}}$ that is initially present and mixed in from the FT, we define a fresh SOA to background $\mathrm{OA}$ ratio:

$r_{\mathrm{FB}}=\frac{\mathrm{OA}_{\mathrm{TERP}}}{\mathrm{OA}_{\mathrm{BG}}}$.

This ratio can be interpreted as follows: for $r_{\mathrm{FB}} \ll 1$ the $\mathrm{OA}_{\mathrm{BG}}$ dominates and the $C_{\mathrm{OA}}$ will be determined by the dilution of this background organic aerosol. When $r_{\mathrm{FB}} \sim 1$, there is an equal contribution of background and newly formed OA. For $r_{\mathrm{FB}} \gg 1$, the $C_{\mathrm{OA}}$ is determined completely by the formation of SOA during the day. However, values of $r_{\mathrm{FB}} \gg 1$ are not expected to be common, since the partitioning of the semi-volatile products into the aerosol phase depends on $\mathrm{OA}_{\mathrm{BG}}$ (see Eq. 1 and Fig. 2). For an initial $\mathrm{OA}_{\mathrm{BG}}$ in the FT 

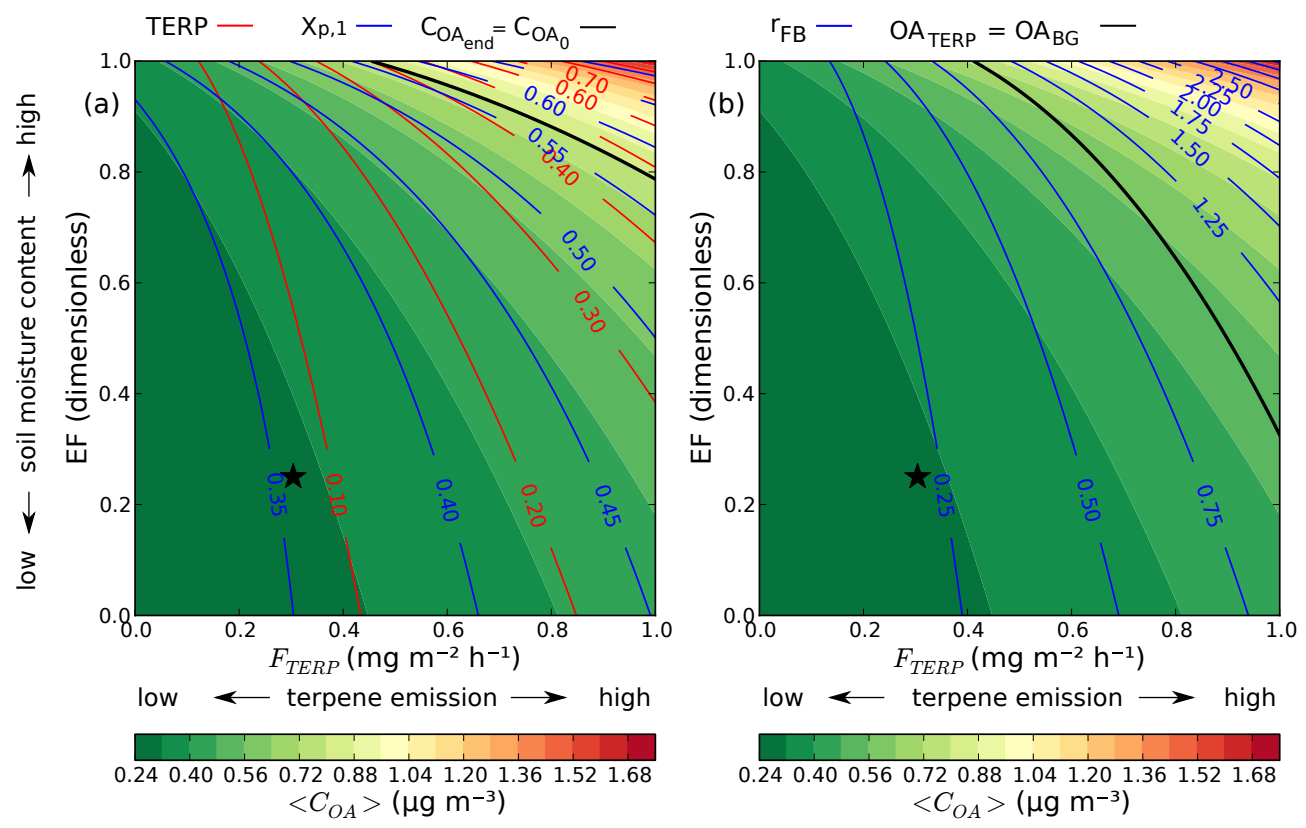

Fig. 9. (a) Sensitivity of organic aerosol concentration $C_{\mathrm{OA}}$ and TERP concentration at 18:50 LT to terpene emission $\left(F_{\mathrm{TERP}}\right)$ and evaporative fraction (EF). Shades indicate organic aerosol concentration $C_{\mathrm{OA}}\left(\mu \mathrm{g} \mathrm{m}^{-3}\right)$, the red contours the TERP concentration $\left(\mu \mathrm{g} \mathrm{m}{ }^{-3}\right)$, and the blue contours the partitioning coefficient $X_{p, 1}$. The black line indicates the conditions for which the $C_{\mathrm{OA}}$ at the end of the day equals the initial concentration, and the asterisk indicates the conditions for the case study. (b) Sensitivity of organic aerosol concentration $C_{\mathrm{OA}}$ and the OA chemistry background ratio $r_{\mathrm{FB}}$ at 18:50 LT to $F_{\mathrm{TERP}}$ and EF. Shades indicate $C_{\mathrm{OA}}\left(\mu \mathrm{g} \mathrm{m}{ }^{-3}\right)$ and the blue contours $r_{\mathrm{FB}}$. The black line indicates the conditions for which the $C_{\mathrm{OA}}$ consists of equal parts of $\mathrm{OA}_{\mathrm{TERP}}$ and $\mathrm{OA}_{\mathrm{BG}}\left(r_{\mathrm{FB}}=1\right)$, and the asterisk indicates the conditions for the case study.

of $0.2 \mu \mathrm{g} \mathrm{m}{ }^{-3}$, the $r_{\mathrm{FB}}=0.22$ at $18: 50$. This further demonstrates the dominating effect of the background aerosol on the $C_{\mathrm{OA}}$ in the $\mathrm{BL}$ for the case study.

\subsection{Sensitivity analysis}

\subsubsection{Response of $C_{\mathrm{OA}}$ to land surface conditions}

As shown in the previous budget analyses, it is important to reproduce accurately both the BL dynamics and chemistry tendency, since they together determine the concentration of a given species. We therefore extend our analysis to analyze the role of land surface in driving both dynamics and chemistry. The land surface determines how much terpenes are emitted and into what size mixing volume by regulating the partitioning between sensible and latent heat flux (see Fig. 7 of the TERP budget). The partitioning of the heat flux governs the growth of the BL, with a much larger growth when sensible flux dominates over latent heat flux $(\mathrm{EF} \sim 0)$, i.e. for dry surface conditions. Under these conditions, the sensible heat flux will strongly heat the BL, which decreases the temperature jump between the BL and FT. This further facilitates the entrainment of warm air from the FT into the BL, which subsequently enhances the BL growth. Conversely, the BL grows less rapidly when the latent heat flux dominates $(\mathrm{EF} \sim 1)$ under very moist surface conditions. This is due to

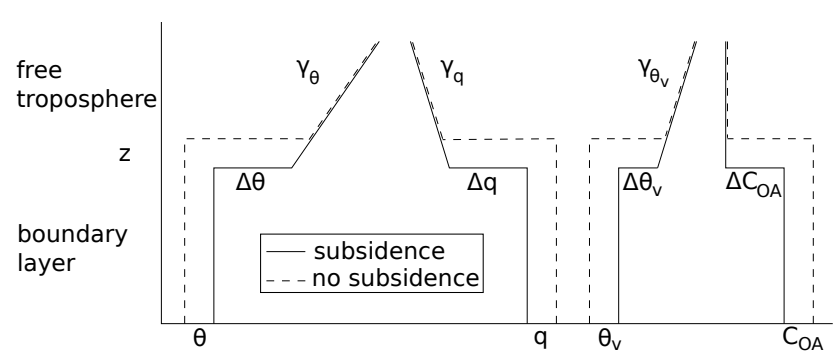

Fig. 10. Sketches of the vertical profiles of $\theta, q, \theta_{\mathrm{v}}$ and $C_{\mathrm{OA}}$ at the end of the day (18:50), in cases of subsidence and no subsidence. A $\Delta$ indicates the jump of a scalar or reactant $C$ defined as $\Delta C=$ $C_{\mathrm{FT}}-\langle C\rangle$ and a $\gamma_{C}$ the lapse rate of a scalar $C$ in the FT.

the fact that for a high EF, most available energy is used to evaporate water from the surface and there is little left for BL growth. In Fig. 10, typical vertical profiles of $\theta$ and $q$ are sketched, to illustrate these effects. Therefore, our first sensitivity analysis addresses the role of different combinations of evaporative fraction $(\mathrm{EF})$ and terpene emission flux $\left(F_{\mathrm{TERP}}\right)$ on the diurnal evolution of $C_{\mathrm{OA}}$. We explore the complete range of possible conditions of EF: from a BL driven solely by the sensible heat flux $(E F=0)$ to a $B L$ driven only by the evaporation flux $(\mathrm{EF}=1)$. Similarly, $F_{\mathrm{TERP}}$ ranges from 
0 to $1 \mathrm{mg} \mathrm{m}^{-2} \mathrm{~h}^{-1}$, which encompasses the range of terpene fluxes observed at the SMEAR II station (Rinne et al., 2007).

Figure $9 \mathrm{a}$ shows the calculated $C_{\mathrm{OA}}$ and TERP concentration at 18:50. The conditions of EF and $F_{\mathrm{TERP}}$ for the case study discussed above are indicated in the figure. As expected, $C_{\mathrm{OA}}$ always increases with larger $F_{\mathrm{TERP}}$ due to the higher formation rate of biogenic SOA. It also increases with $\mathrm{EF}$, because shallower boundary layers, weaker entrainment and thus less mixing of FT air with low OA concentrations occur when the land surface is dominated by the evaporation flux. The effect on temperature acts in the same direction, i.e. a higher EF leads both to a lower sensible heat flux into the BL and to less entrainment of relatively warm free tropospheric air. Consequently, the temperature in the mixed layer becomes lower. The temperature decreases by $6 \mathrm{~K}$ in the experiment going from $E F=0$ to $E F=1$. Because of the lower temperatures, more semi-volatile material will partition into the aerosol phase, but this has only a minor effect compared to the changes in dilution. This becomes clear from the partitioning coefficient $X_{\mathrm{p}}$, which is shown together with $C_{\mathrm{OA}}$ in Fig. 9a for the semi-volatile product $\mathrm{C}_{1}, X_{\mathrm{p}}$ depends on $C_{\mathrm{OA}}$ and T, following Eqs. (1) and (2). Here, we find that $X_{\mathrm{p}}$ closely follows the behavior of $C_{\mathrm{OA}}$, and only a slight deviation from this pattern is caused by the dependence of $X_{\mathrm{p}}$ on $T$. The $T$ dependence is the most pronounced for low EF, when a large sensible heat flux leads to a larger heating of the $\mathrm{BL}$ and consequently a large entrainment of relatively warm air from the FT.

Based on the relationship between $C_{\mathrm{OA}}$ and TERP concentration, we can distinguish 2 different regimes: one characterized by soils with low moisture content $(\mathrm{EF}<0.5)$ and low terpene emissions $\left(F_{\mathrm{TERP}}<0.6\right)$ and another characterized by high moisture content (i.e. wet soil) and strong terpene emissions. Dry soil causes larger sensible heat fluxes, which lead to rapid $\mathrm{BL}$ growth and enhance dilution of $C_{\mathrm{OA}}$ due to entrainment of air from the FT. For TERP, on the other hand, the entrainment term has a minor contribution to the total tendency (due to the shorter lifetime of this species), which is dominated by the emissions and the chemical destruction (see Fig. 7). Since $C_{\mathrm{OA}}$ and TERP are dominated by different processes in this regime, their tendencies are not strongly related. In this regime, the role of entrainment will dominate over that of chemistry.

For a wet soil $(\mathrm{EF}>0.5)$ and high emissions $\left(F_{\mathrm{TERP}}>0.6\right)$, on the other hand, we are in a regime where chemistry plays a larger role in determining the tendency of $C_{\mathrm{OA}}$. Here, the larger emission contributes more to the $C_{\mathrm{OA}}$ tendency, while the low sensible heat flux results in weak BL growth and entrainment. The combined effect of higher emissions into shallower BL causes a significant contribution of chemistry to the $C_{\mathrm{OA}}$ tendency. Only in the upper right corner of Fig. 9 do we find conditions for which there is a net increase of $C_{\mathrm{OA}}$ during the day, since here condensation outweighs entrainment. These conditions are delimited by the black con- tour. In this regime, $C_{\mathrm{OA}}$ and TERP are strongly related since there the influence of entrainment is relatively small.

The consequences of this sensitivity of $C_{\mathrm{OA}}$ for conditions of the case study can be deduced from Fig. 9a. $C_{\mathrm{OA}}$ at a terpene emission flux of $304 \mathrm{mg} \mathrm{m}^{-2} \mathrm{~h}^{-1}$ ranges from 0.30 to $0.62 \mu \mathrm{g} \mathrm{m}^{-3}$, a difference of a factor of 2, when the EF increases from 0 to 1 . For a constant $\mathrm{EF}$ of 0.25 and $F_{\mathrm{TERP}}$ ranging from 0 to $1 \mathrm{mg} \mathrm{m}^{-2} \mathrm{~h}^{-1}, C_{\mathrm{OA}}$ could range from 0.26 to $0.49 \mu \mathrm{g} \mathrm{m}^{-3}$, a difference of almost a factor of 2 . On the other hand, in the dry regime with a low emission there is a large range of conditions of EF and $F_{\text {TERP }}$ which can lead to a certain observed $C_{\mathrm{OA}}$. An observed $C_{\mathrm{OA}}$ of $0.31 \mu \mathrm{g} \mathrm{m}^{-3}$, as in the case study, could result from $\mathrm{EF}=0$ and $F_{\mathrm{TERP}}=0.4$, but also from $\mathrm{EF}=0.9$ and $F_{\mathrm{TERP}}=0$.

Figure $9 \mathrm{~b}$ shows the behavior of $r_{\mathrm{FB}}$ as a function of $\mathrm{EF}$ and $F_{\text {TERP. }}$. The entrainment and chemistry limited regimes are also well developed here: for low EF and $F_{\text {TERP }}$ the background aerosol dominates, while for wet soils $(\mathrm{EF}>0.3)$ and $F_{\text {TERP }}>0.4, r_{\mathrm{FB}}$ becomes larger than 1, meaning that there is more $\mathrm{OA}_{\mathrm{TERP}}$ present than $\mathrm{OA}_{\mathrm{BG}}$. There is a wide range of conditions for which they are equally important: from $\mathrm{EF}=1$ and $F_{\mathrm{TERP}} \sim 0.4$ to $\mathrm{EF} \sim 0.3$ and $F_{\mathrm{TERP}}=1$.

\subsubsection{Combined response of $C_{\mathrm{OA}}$ to subsidence and land surface conditions}

As indicated in Fig. 1 and in order to complete our analysis, it is interesting to analyze the role of subsidence because on summer days, high pressure systems typically prevent the BL growth by inducing downward air motions. This was, for example, the case over Finland during the HUMPPA-COPEC campaign in summer 2010 (Williams et al., 2011). Further, the soil moisture content determines the partitioning of the surface heat fluxes and thus the energy that is available for BL growth and entrainment.

To understand the influence of subsidence, it is important to note that its effect is twofold: it suppresses BL growth while simultaneously enhancing entrainment. The suppression of BL growth becomes clear when looking at the equation for BL growth, which is the net result of the entrainment velocity $w_{\mathrm{e}}$ on one hand and the subsidence velocity $w_{\mathrm{s}}$ on the other:

$\frac{d h}{d t}=w_{\mathrm{e}}+w_{\mathrm{s}}$.

In the analysis, we prescribe the large-scale subsidence rate $\left(\omega\left(\mathrm{s}^{-1}\right)\right)$, defined as the divergence of the horizontal mean wind. It can be thought of as the fraction with which the BL is pushed down each second due to large-scale vertical subsiding motions. The subsidence velocity $\left(w_{\mathrm{s}}\left(\mathrm{m} \mathrm{s}^{-1}\right)\right)$, with a typical order of magnitude of $10^{-2} \mathrm{~m} \mathrm{~s}^{-1}$, is therefore in our modeling approach represented as:

$w_{\mathrm{s}}=-\omega h$.

To understand the effects of subsidence on entrainment, we need to analyze the expression to calculate $w_{\mathrm{e}}$. It is a 

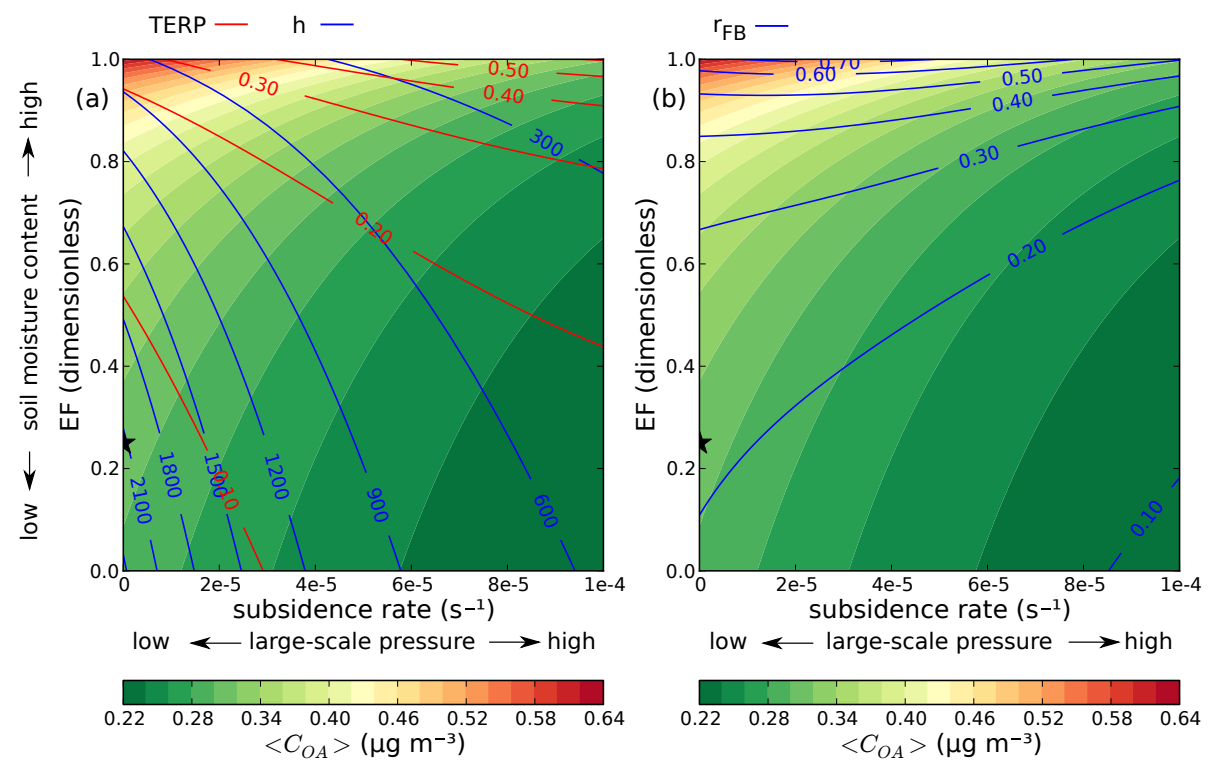

Fig. 11. (a) Sensitivity of organic aerosol concentration $\left(C_{\mathrm{OA}}\right)$, BL height $(h)$ and TERP concentration at 18:50 LT to subsidence and evaporative fraction (EF). Shades indicate $C_{\mathrm{OA}}\left(\mu \mathrm{g} \mathrm{m}^{-3}\right)$, the blue contours $h(\mathrm{~m})$, and the red contours TERP concentration $\left(\mu \mathrm{gm} \mathrm{m}^{-3}\right)$. $(\mathbf{b})$ Sensitivity of $C_{\mathrm{OA}}$ and the the OA chemistry background ratio $\left(r_{\mathrm{FB}}\right)$ at 18:50 LT to subsidence and evaporative fraction (EF). Shades indicate $C_{\mathrm{OA}}\left(\mu \mathrm{g} \mathrm{m}^{-3}\right)$ and the blue contours $r_{\mathrm{FB}}$ (dimensionless). The asterisk indicates the conditions for the case study.

function of the buoyancy flux and the virtual potential temperature jump between the BL and the FT $\left(\Delta \theta_{\mathrm{v}}\right)$ (van Heerwaarden et al., 2009):

$w_{\mathrm{e}}=\frac{\beta \overline{\left(w^{\prime} \theta_{\mathrm{v}}^{\prime}\right)_{\mathrm{s}}}}{\Delta \theta_{\mathrm{v}}}$

where $\beta$ is the (fixed) ratio between the entrainment and surface buoyancy flux (dimensionless), $\overline{\left(w^{\prime} \theta_{\mathrm{v}}^{\prime}\right)_{\mathrm{s}}}$ is the surface buoyancy flux $\left(\mathrm{Km} \mathrm{s}^{-1}\right)$, and $\Delta \theta_{\mathrm{v}}$ is the jump of the virtual potential temperature between the BL and FT, defined as:

$\Delta \theta_{\mathrm{v}}=\Delta \theta+0.61(\langle q\rangle \Delta \theta+\langle\theta\rangle \Delta q+\Delta \theta \Delta q)$

$\simeq \Delta \theta+0.61\langle\theta\rangle \Delta q$

where $\Delta \theta$ and $\Delta q$ are the differences in $\theta$ and $q$ between the BL and the FT, respectively. Figure 10 shows sketches of typical vertical profiles of $\theta, q, \theta_{\mathrm{v}}$ and $C_{\mathrm{OA}}$ for conditions with and without subsidence to illustrate these effects.

For a constant EF, the buoyancy flux and therefore the numerator in Eq. (8) remain constant. Consequently, subsidence only affects $w_{\mathrm{e}}$ through $\Delta \theta_{\mathrm{v}}$. In case of subsidence, the same amount of sensible heat is introduced into a shallower BL, so $\langle\theta\rangle$ increases and $\Delta \theta$ decreases. The specific moisture $(\langle q\rangle)$, however, decreases with subsidence, because the increase in moisture due to evaporation into a smaller mixing volume is offset by the enhanced entrainment of dry air. $\Delta q$ is therefore smaller in the case with subsidence. Taken together, these effects result in a smaller $\Delta \theta_{\mathrm{v}}$ in the case of subsidence: the effect of $\Delta \theta$ on $\Delta \theta_{\mathrm{v}}$ is only partly compensated by the effect of $\Delta q$ through the second term on the RHS of Eq. (9). In all our experiments, we find that $w_{\mathrm{e}}$ is enhanced when subsidence increases. This means that the enhanced entrainment due to a stronger heating of the BL is further enhancing itself by diminishing $\Delta \theta_{\mathrm{v}}$. For $\mathrm{EF}=1$, the daily average $w_{\mathrm{e}}$ ranges from $1 \mathrm{~cm} \mathrm{~s}^{-1}$ when there is no subsidence to $2 \mathrm{~cm} \mathrm{~s}^{-1}$ for $\omega=1 \times 10^{-4} \mathrm{~s}^{-1}$.

Figure 11a shows the sensitivity of $C_{\mathrm{OA}}$ to $\mathrm{EF}$, ranging from 0 to 1 , and subsidence ranging from no subsidence $\left(\omega=0 \mathrm{~s}^{-1}\right)$ to strong subsidence $\left(\omega=1 \times 10^{-4} \mathrm{~s}^{-1}\right)$. By increasing EF, BL height decreases and both $C_{\mathrm{OA}}$ and TERP concentration increase. As in the previous sensitivity analysis, the highest sensitivity is found for wet soils. BL height decreases rapidly when $\mathrm{EF}>0.8$, which leads to an increase of $C_{\mathrm{OA}}$ by $\sim 50 \%$ over the whole subsidence range, e.g. from 0.31 to $0.44 \mu \mathrm{g} \mathrm{m}^{-3}$ at $\omega=5 \times 10^{-5} \mathrm{~s}^{-1}$. TERP concentration doubles for an EF ranging from 0.8 to 1.0, e.g. from 0.24 to $0.48 \mu \mathrm{g} \mathrm{m}^{-3}$ at $\omega=5 \times 10^{-5} \mathrm{~s}^{-1}$. However, $C_{\mathrm{OA}}$ decreases while TERP concentrations increase with stronger subsidence. For $C_{\mathrm{OA}}$, this is because there is a stronger dilution due to entrainment with increasing subsidence. Since OA has a large background fraction compared to the production of SOA from TERP (Fig. 8), the enhanced dilution means that $C_{\mathrm{OA}}$ decreases despite the lower BL height. TERP concentrations, on the other hand, increase with larger subsidence values, because they are emitted into a shallower BL. Enhanced entrainment partly compensates for this, but has only a small effect on the TERP concentration due to the relatively short lifetime of this species (see also Fig. 7). The consequence is that under all conditions considered in our case study, the behavior of $C_{\mathrm{OA}}$ is unrelated to that of 
TERP, due to the different roles that entrainment, emission and chemistry have on their respective budgets.

Figure $11 \mathrm{~b}$ shows the behavior of $r_{\mathrm{FB}}$ for varying subsidence and EF. $r_{\mathrm{FB}}$ is always below 1, because of the low for-

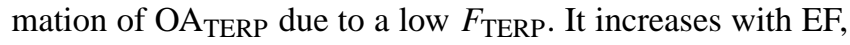
because both $C_{\mathrm{OA}}$, which enhances the partitioning into the aerosol phase, and TERP increase. For a changing $\omega$ and low $\mathrm{EF}(<0.8)$, it decreases with increasing $\omega$, because the enhanced dilution of $\mathrm{OA}_{\mathrm{BG}}$ affects the partitioning negatively. For EF $>0.8$, however, $r_{\mathrm{FB}}$ shows some interesting nonlinear behavior: at $\omega=4 \times 10^{-5}, r_{\mathrm{FB}}$ has a maximum, because there the combination of a high TERP concentration and a high $X_{\mathrm{p}}$, caused by high $C_{\mathrm{OA}}$, result in the partitioning of a large fraction of $C_{i}$ into the aerosol phase.

\section{Conclusions}

We have studied the integrated effects of land surface, chemistry, and entrainment on the diurnal evolution of SOA, using MXLCH-SOA, a model that reproduces the dynamics of a diurnal convective atmospheric boundary layer and the chemical transformations of terpenes and their oxidants that lead to SOA formation (Fig. 1).

MXLCH-SOA is able to reproduce the diurnal variability of SOA production and relate it with the observed dynamics and gas-phase chemistry for a characteristic case study in the boreal forest. Our findings indicate the importance of including entrainment to explain the observed diurnal cycle in SOA concentration, and suggest that entrainment may contribute ten times more to the total tendency than SOA production during daytime. This contribution is due to a large volume of air that is entrained from the residual layer during the rapid growth of the boundary layer in the morning. A sensitivity analysis further suggests that the boreal forest is in a regime where relatively low terpene emissions are the limiting factor for SOA formation. For environments or situations with wet soils and high VOC emissions, e.g. the tropics, the effects of entrainment may be weaker, and the SOA concentration and VOC concentration may therefore show a stronger relationship. Furthermore, we also find that under conditions of subsidence there is no straightforward relation between organic aerosol concentrations and terpene concentrations.

Measured SOA and VOC concentrations are the net result of emissions, chemistry and dynamics. To interpret these measurements, it is important to include observations of all of these components in the design of field campaigns. More specifically, the role of the increase of SOA during the night both in the residual layer and in the nocturnal stable boundary layer will be an important factor to understand, since for most studied situations, the SOA evolution during daytime is mainly driven by entrainment. Therefore, it is essential to have early morning profiles of $C_{\mathrm{OA}}$ to characterize both the initial concentration in the nocturnal stable BL and the organic aerosol that has built up in the residual layer, because this will be entrained into the convective boundary layer during the morning. Further, to understand ambient SOA concentrations it may be equally important to characterize BL height and entrainment as it is to understand the temperature dependence of the saturation concentration of the semivolatile species.

Our findings are also important for regional and global modeling studies: the strong sensitivity of $C_{\mathrm{OA}}$ to land surface and FT conditions means that uncertainties in the representation of these components may strongly affect the simulated $C_{\mathrm{OA}}$. To model $C_{\mathrm{OA}}$ accurately, large-scale models should be able to reproduce the coupling between the land surface, boundary layer dynamics, free troposphere conditions and chemistry and the resulting behavior of organic aerosol and terpene concentrations as presented in the sensitivity analyses. Due to the wide range of conditions under study (Figs. 9 and 11), our findings can be used to quantify the uncertainty that arises from inaccurately representing these processes in large-scale models. Besides, our results indicate that box models are only applicable for studying ambient SOA formation when they account for boundary layer growth and entrainment and when background organic aerosol levels are well constrained.

Future research on the diurnal evolution of SOA concentrations will include an interactive land surface, since both surface heat fluxes (van Heerwaarden et al., 2009) and terpene emissions (Guenther et al., 1995; Niinemets et al., 2010) are the result of the interaction of the BL with the land surface.

In summary, our findings indicate that in order to understand the diurnal evolution of SOA in the boundary layer the coupled effects of the land surface, dynamics of the atmospheric boundary layer, chemistry, and free troposphere conditions should be studied simultaneously. A balanced representation of all these processes should be considered when preparing and conducting both field campaigns and modeling.

\section{Appendix A}

\section{Derivation of the $C_{\mathrm{OA}}$ budget}

We derive the budget equation of $C_{\mathrm{OA}}$ by taking the time derivative of Eq. (1):

$\frac{d C_{\mathrm{OA}}}{d t}=\frac{d \mathrm{OA}_{\mathrm{BG}}}{d t}+\sum_{i}\left[X_{p, i} \frac{d C_{i}}{d t}+C_{i} \frac{d X_{p, i}}{d t}\right]$

If $C_{i} \frac{d X_{p, i}}{d t} \ll X_{p, i} \frac{d C_{i}}{d t}$, which is the case for our case study, the former term can be ignored and then Eq. (A1) reduces to:

$\frac{d C_{\mathrm{OA}}}{d t} \simeq \frac{d \mathrm{OA}_{\mathrm{BG}}}{d t}+\sum_{i} X_{p, i} \frac{d C_{i}}{d t}$ 
The individual terms can be further written out as:

$$
\begin{array}{r}
\frac{d C_{i}}{d t}=\overbrace{\frac{w_{e} \Delta C_{i}}{h}}^{\text {entrainment }}+\overbrace{\sum_{j} \alpha_{i} k_{j}\langle\mathrm{TERP}\rangle\left\langle\mathrm{OX}_{j}\right\rangle}^{\text {chemistry }} . \\
\frac{\overbrace{w_{e} \Delta \mathrm{OA}_{\mathrm{BG}}}^{\text {entrainment }}}{h}
\end{array}
$$

Acknowledgements. Christoph Spirig and NCAR are acknowledged for sharing the VOC and dynamics data, Tomi Raatikainen for sharing the OA data, Petri Keronen for his advice on the $\mathrm{NO}_{\mathrm{x}}$ data and Maarten Krol for helpful comments on the manuscript. J. L. J. was supported by NSF ATM-0919189 and DOE (BER, ASR Program) DE-SC0006035. This study was supported by European Commission through the 7th Framework Programme project COMBINE (project No. 226520, Comprehensive Modelling of the Earth System for Better Climate Prediction and Projection). I. M. acknowledges the support from the Academy of Finland Center of Excellence program (project number 1118615).

Edited by: N. Saigusa

\section{References}

Atkinson, R. and Arey, J.: Atmospheric degradation of volatile organic compounds, Chem. Rev., 103, 4605-4638, doi:10.1021/cr0206420, 2003.

Bowman, F. M. and Karamalegos, A. M.: Estimated effects of composition on secondary organic aerosol mass concentrations, Environ. Sci. Technol., 36, 2701-2707, doi:10.1021/es015717g, 2002.

Cappa, C. D. and Jimenez, J. L.: Quantitative estimates of the volatility of ambient organic aerosol, Atmos. Chem. Phys., 10, 5409-5424, doi:10.5194/acp-10-5409-2010, 2010.

de Bruin, H.: A model for the Priestley-Taylor parameter $\alpha$, J. Appl. Meteorol., 22, 572-578, doi:10.1175/15200450(1983)022<0572:AMFTPT>2.0.CO;2, 1983.

Donahue, N. M., Robinson, A. L., Stanier, C. O., and Pandis, S. N.: Coupled partitioning, dilution, and chemical aging of semivolatile organics, Environ. Sci. Technol., 40, 2635-2643, doi:10.1021/es052297c, 2006.

Dzepina, K., Volkamer, R. M., Madronich, S., Tulet, P., Ulbrich, I. M., Zhang, Q., Cappa, C. D., Ziemann, P. J., and Jimenez, J. L.: Evaluation of recently-proposed secondary organic aerosol models for a case study in Mexico City, Atmos. Chem. Phys., 9, 5681-5709, doi:10.5194/acp-9-5681-2009, 2009.

Ganzeveld, L., Eerdekens, G., Feig, G., Fischer, H., Harder, H., Königstedt, R., Kubistin, D., Martinez, M., Meixner, F. X., Scheeren, H. A., Sinha, V., Taraborrelli, D., Williams, J., VilàGuerau de Arellano, J., and Lelieveld, J.: Surface and boundary layer exchanges of volatile organic compounds, nitrogen oxides and ozone during the GABRIEL campaign, Atmos. Chem. Phys., 8, 6223-6243, doi:10.5194/acp-8-6223-2008, 2008.

Guenther, A., Hewitt, C., Erickson, D., Fall, R., Geron, C., Graedel, T., Harley, P., Klinger, L., Lerdau, M., McKay, W.,
Pierce, T., Scholes, B., Steinbrecher, R., Tallamraju, R., Taylor, J., and Zimmerman, P.: A global model of natural volatile organic compound emissions, J. Geophys. Res., 100, 8873-8892, 1995.

Hallquist, M., Wenger, J. C., Baltensperger, U., Rudich, Y., Simpson, D., Claeys, M., Dommen, J., Donahue, N. M., George, C., Goldstein, A. H., Hamilton, J. F., Herrmann, H., Hoffmann, T., Iinuma, Y., Jang, M., Jenkin, M. E., Jimenez, J. L., KiendlerScharr, A., Maenhaut, W., McFiggans, G., Mentel, Th. F., Monod, A., Prévôt, A. S. H., Seinfeld, J. H., Surratt, J. D., Szmigielski, R., and Wildt, J.: The formation, properties and impact of secondary organic aerosol: current and emerging issues, Atmos. Chem. Phys., 9, 5155-5236, doi:10.5194/acp-9-51552009, 2009.

Hao, L. Q., Romakkaniemi, S., Yli-Pirilä, P., Joutsensaari, J., Kortelainen, A., Kroll, J. H., Miettinen, P., Vaattovaara, P., Tiitta, P., Jaatinen, A., Kajos, M. K., Holopainen, J. K., Heijari, J., Rinne, J., Kulmala, M., Worsnop, D. R., Smith, J. N., and Laaksonen, A.: Mass yields of secondary organic aerosols from the oxidation of $\alpha$-pinene and real plant emissions, Atmos. Chem. Phys., 11, 1367-1378, doi:10.5194/acp-11-1367-2011, 2011.

Hari, P. and Kulmala, M.: Station for Measuring EcosystemAtmosphere Relations (SMEAR II), Boreal Environ. Res., 10, 315-322, 2005.

Heald, C. L., Coe, H., Jimenez, J. L., Weber, R. J., Bahreini, R., Middlebrook, A. M., Russell, L. M., Jolleys, M., Fu, T.-M., Allan, J. D., Bower, K. N., Capes, G., Crosier, J., Morgan, W. T., Robinson, N. H., Williams, P. I., Cubison, M. J., DeCarlo, P. F., and Dunlea, E. J.: Exploring the vertical profile of atmospheric organic aerosol: comparing 17 aircraft field campaigns with a global model, Atmos. Chem. Phys., 11, 12673-12696, doi:10.5194/acp-11-12673-2011, 2011.

Henry, K. M. and Donahue, N. M.: Effect of the OH radical scavenger hydrogen peroxide on secondary organic aerosol formation from $\alpha$-pinene ozonolysis, Aerosol Sci. Technol., 45, 696-700, doi:10.1080/02786826.2011.552926, 2011.

Jimenez, J. L., Canagaratna, M. R., Donahue, N. M., Prevot, A. S. H., Zhang, Q., Kroll, J. H., DeCarlo, P. F., Allan, J. D., Coe, H., Ng, N. L., Aiken, A. C., Docherty, K. S., Ulbrich, I. M., Grieshop, A. P., Robinson, A. L., Duplissy, J., Smith, J. D., Wilson, K. R., Lanz, V. A., Hueglin, C., Sun, Y. L., Tian, J., Laaksonen, A., Raatikainen, T., Rautiainen, J., Vaattovaara, P., Ehn, M., Kulmala, M., Tomlinson, J. M., Collins, D. R., Cubison, M. J., E, Dunlea, J., Huffman, J. A., Onasch, T. B., Alfarra, M. R., Williams, P. I., Bower, K., Kondo, Y., Schneider, J., Drewnick, F., Borrmann, S., Weimer, S., Demerjian, K., Salcedo, D., Cottrell, L., Griffin, R., Takami, A., Miyoshi, T., Hatakeyama, S., Shimono, A., Sun, J. Y., Zhang, Y. M., Dzepina, K., Kimmel, J. R., Sueper, D., Jayne, J. T., Herndon, S. C., Trimborn, A. M., Williams, L. R., Wood, E. C., Middlebrook, A. M., Kolb, C. E., Baltensperger, U., and Worsnop, D. R.: Evolution of organic aerosols in the atmosphere, Science, 326, 1525-1529, 2009.

Junninen, H., Lauri, A., Keronen, P., Aalto, P., Hiltunen, V., Hari, P., and Kulmala, M.: Smart-SMEAR: on-line data exploration and visualization tool for SMEAR stations, Boreal Environ. Res., 14, 447-457, 2009.

Krol, M. C., Molemaker, M. J., and Vilà-Guerau de Arellano, J.: Effects of turbulence and heterogeneous emissions on photochemi- 
cally active species in the convective boundary layer, J. Geophys. Res., 105, 6871-6884, 2000.

Laaksonen, A., Kulmala, M., O’Dowd, C. D., Joutsensaari, J., Vaattovaara, P., Mikkonen, S., Lehtinen, K. E. J., Sogacheva, L., Dal Maso, M., Aalto, P., Petäjä, T., Sogachev, A., Yoon, Y. J., Lihavainen, H., Nilsson, D., Facchini, M. C., Cavalli, F., Fuzzi, S., Hoffmann, T., Arnold, F., Hanke, M., Sellegri, K., Umann, B., Junkermann, W., Coe, H., Allan, J. D., Alfarra, M. R., Worsnop, D. R., Riekkola, M.-L., Hyötyläinen, T., and Viisanen, Y.: The role of VOC oxidation products in continental new particle formation, Atmos. Chem. Phys., 8, 2657-2665, doi:10.5194/acp-8-2657-2008, 2008.

Lane, T. E., Donahue, N. M., and Pandis, S. N.: Simulating secondary organic aerosol formation using the volatility basis-set approach in a chemical transport model, Atmos. Environ., 42, 7439-7451, doi:10.1016/j.atmosenv.2008.06.026, 2008.

Lilly, D. K.: Models of cloud-topped mixed layers under a strong inversion, Q. J. Roy. Meteor. Soc., 94, 292-309, 1477-870X, 1968.

Mammarella, I., Launiainen, S., Gronholm, T., Keronen, P., Pumpanen, J., Rannik, Ü. and Vesala, T.: Relative humidity effect on the high-frequency attenuation of water vapor flux measured by a closed-path eddy covariance system, J. Atmos. Oceanic Technol., 26, 1856-1866, doi:10.1175/2009JTECHA1179.1, 2009.

Martin, C. L., Fitzjarrald, D., Garstang, M., Oliveira, A. P., Greco, S., and Browell, E.: Structure and growth of the mixing layer over the Amazonian rain forest, J. Geophys. Res., 93, 13611375, doi:10.1029/JD093iD02p01361, 1988.

Metzger, A., Verheggen, B., Dommen, J., Duplissy, J., Prevot, A. S. H., Weingartner, E., Riipinen, I., Kulmala, M., Spracklen, D. V., Carslaw, K. S., and Baltensperger, U.: Evidence for the role of organics in aerosol particle formation under atmospheric conditions, Proc. Natl. Acad. Sci., 107, 6646-6651, 2010.

Niinemets, Ü., Monson, R. K., Arneth, A., Ciccioli, P., Kesselmeier, J., Kuhn, U., Noe, S. M., Peñuelas, J., and Staudt, M.: The leaf-level emission factor of volatile isoprenoids: caveats, model algorithms, response shapes and scaling, Biogeosciences, 7, 1809-1832, doi:10.5194/bg-7-1809-2010, 2010.

O’Dowd, C. D., Aalto, P., Hämeri, K., Kulmala, M., and Hoffmann, T.: Aerosol formation: atmospheric particles from organic vapours, Nature, 416, 497-498, doi:10.1038/416497a, 2002.

Pankow, J. F.: An absorption model of the gas/aerosol partitioning involved in the formation of secondary organic aerosol, Atmos. Environ., 28, 189-193, doi:10.1016/1352-2310(94)900949, 1994.

Pathak, R. K., Presto, A. A., Lane, T. E., Stanier, C. O., Donahue, N. M., and Pandis, S. N.: Ozonolysis of $\alpha$-pinene: parameterization of secondary organic aerosol mass fraction, Atmos. Chem. Phys., 7, 3811-3821, doi:10.5194/acp-7-3811-2007, 2007.

Petäjä, T., Mauldin, III, R. L., Kosciuch, E., McGrath, J., Nieminen, T., Paasonen, P., Boy, M., Adamov, A., Kotiaho, T., and Kulmala, M.: Sulfuric acid and $\mathrm{OH}$ concentrations in a boreal forest site, Atmos. Chem. Phys., 9, 7435-7448, doi:10.5194/acp9-7435-2009, 2009.

Pöschl, U., Martin, S. T., Sinha, B., Chen, Q., Gunthe, S. S., Huffman, J. A., Borrmann, S., Farmer, D. K., Garland, R. M., Helas, G., Jimenez, J. L., King, S. M., Manzi, A., Mikhailov, E., Pauliquevis, T., Petters, M. D., Prenni, A. J., Roldin, P.,
Rose, D., Schneider, J., Su, H., Zorn, S. R., Artaxo, P., and Andreae, M. O.: Rainforest aerosols as biogenic nuclei of clouds and precipitation in the Amazon, Science, 329, 1513-1516, doi:10.1126/science.1191056, 2010.

Raatikainen, T., Vaattovaara, P., Tiitta, P., Miettinen, P., Rautiainen, J., Ehn, M., Kulmala, M., Laaksonen, A., and Worsnop, D. R.: Physicochemical properties and origin of organic groups detected in boreal forest using an aerosol mass spectrometer, Atmos. Chem. Phys., 10, 2063-2077, doi:10.5194/acp-10-2063-2010, 2010.

Riipinen, I., Pierce, J. R., Yli-Juuti, T., Nieminen, T., Häkkinen, S., Ehn, M., Junninen, H., Lehtipalo, K., Petäjä, T., Slowik, J., Chang, R., Shantz, N. C., Abbatt, J., Leaitch, W. R., Kerminen, V.-M., Worsnop, D. R., Pandis, S. N., Donahue, N. M., and Kulmala, M.: Organic condensation: a vital link connecting aerosol formation to cloud condensation nuclei $(\mathrm{CCN})$ concentrations, Atmos. Chem. Phys., 11, 3865-3878, doi:10.5194/acp11-3865-2011, 2011.

Rinne, J., Taipale, R., Markkanen, T., Ruuskanen, T. M., Hellén, H., Kajos, M. K., Vesala, T., and Kulmala, M.: Hydrocarbon fluxes above a Scots pine forest canopy: measurements and modeling, Atmos. Chem. Phys., 7, 3361-3372, doi:10.5194/acp-7-33612007, 2007.

Ruuskanen, T. M., Taipale, R., Rinne, J., Kajos, M. K., Hakola, H., and Kulmala, M.: Quantitative long-term measurements of VOC concentrations by PTR-MS: annual cycle at a boreal forest site, Atmos. Chem. Phys. Discuss., 9, 81-134, doi:10.5194/acpd-981-2009, 2009.

Sheehan, P. E. and Bowman, F. M.: Estimated effects of temperature on secondary organic aerosol concentrations, Environ. Sci. Technol., 35, 2129-2135, 2001.

Slowik, J. G., Stroud, C., Bottenheim, J. W., Brickell, P. C., Chang, R. Y.-W., Liggio, J., Makar, P. A., Martin, R. V., Moran, M. D., Shantz, N. C., Sjostedt, S. J., van Donkelaar, A., Vlasenko, A., Wiebe, H. A., Xia, A. G., Zhang, J., Leaitch, W. R., and Abbatt, J. P. D.: Characterization of a large biogenic secondary organic aerosol event from eastern Canadian forests, Atmos. Chem. Phys., 10, 2825-2845, doi:10.5194/acp-10-28252010, 2010.

Spirig, C., Guenther, A., Greenberg, J. P., Calanca, P., and Tarvainen, V.: Tethered balloon measurements of biogenic volatile organic compounds at a Boreal forest site, Atmos. Chem. Phys., 4, 215-229, doi:10.5194/acp-4-215-2004, 2004.

Tennekes, H.: A model for the dynamics of the inversion above a convective boundary layer, J. Atmos. Sci., 30, 558-567, 1973.

Tsimpidi, A. P., Karydis, V. A., Zavala, M., Lei, W., Molina, L., Ulbrich, I. M., Jimenez, J. L., and Pandis, S. N.: Evaluation of the volatility basis-set approach for the simulation of organic aerosol formation in the Mexico City metropolitan area, Atmos. Chem. Phys., 10, 525-546, doi:10.5194/acp-10-525-2010, 2010.

Tunved, P., Hansson, H. C., Kerminen, V. M., Strom, J., Maso, M. D., Lihavainen, H., Viisanen, Y., Aalto, P. P., Komppula, M., and Kulmala, M.: High natural aerosol loading over boreal forests, Science, 312, 261-263, 2006.

van Heerwaarden, C. C., Vilà-Guerau de Arellano, J., Moene, A. F., and Holtslag, A. A. M.: Interactions between dry-air entrainment, surface evaporation and convective boundary-layer development, Q. J. Roy. Meteor. Soc., 135, 1277-1291, doi:10.1002/qj.431, 2009. 
Vilà-Guerau de Arellano, J., Patton, E. G., Karl, T., van den Dries, K., Barth, M. C., and Orlando, J. J.: The role of boundary layer dynamics on the diurnal evolution of isoprene and the hydroxyl radical over tropical forests, J. Geophys. Res., 116, D07304, 2011.

Williams, J., Crowley, J., Fischer, H., Harder, H., Martinez, M., Petäjä, T., Rinne, J., Bäck, J., Boy, M., Dal Maso, M., Hakala, J., Kajos, M., Keronen, P., Rantala, P., Aalto, J., Aaltonen, H., Paatero, J., Vesala, T., Hakola, H., Levula, J., Pohja, T., Herrmann, F., Auld, J., Mesarchaki, E., Song, W., Yassaa, N., Nölscher, A., Johnson, A. M., Custer, T., Sinha, V., Thieser, J., Pouvesle, N., Taraborrelli, D., Tang, M. J., Bozem, H., Hosaynali-Beygi, Z., Axinte, R., Oswald, R., Novelli, A., Kubistin, D., Hens, K., Javed, U., Trawny, K., Breitenberger, C., Hidalgo, P. J., Ebben, C. J., Geiger, F. M., Corrigan, A. L., Russell, L. M., Ouwersloot, H. G., Vilà-Guerau de Arellano, J., Ganzeveld, L., Vogel, A., Beck, M., Bayerle, A., Kampf, C. J., Bertelmann, M., Köllner, F., Hoffmann, T., Valverde, J., González, D., Riekkola, M.-L., Kulmala, M., and Lelieveld, J.: The summertime Boreal forest field measurement intensive (HUMPPA-COPEC-2010): an overview of meteorological and chemical influences, Atmos. Chem. Phys., 11, 1059910618, doi:10.5194/acp-11-10599-2011, 2011. 